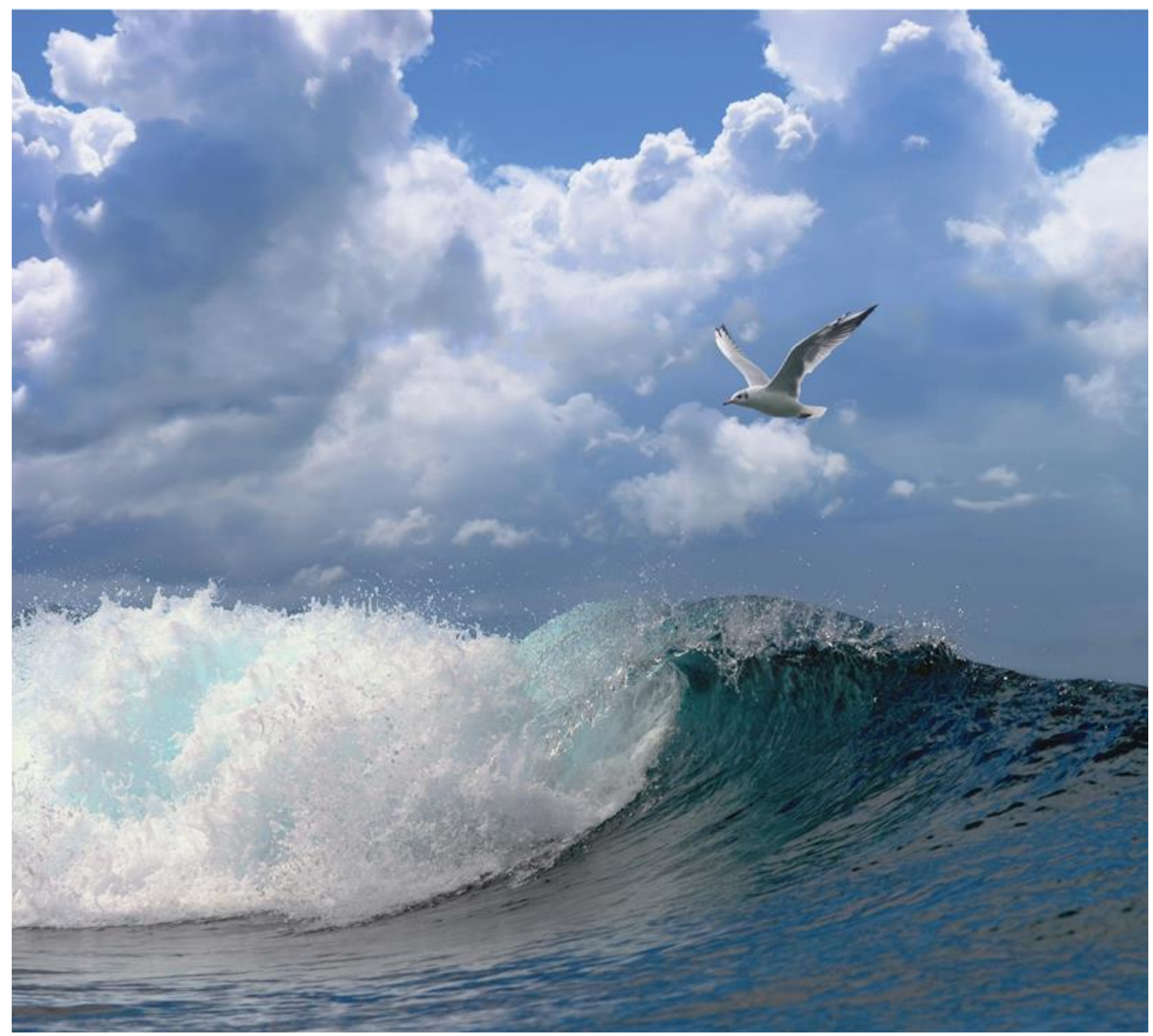

Authors: Sander Lagerveld, René Janssen, Jasper Manshanden, Anne-Jifke Haarsma, Simon de Wageningen University \& Vries, Robin Brabant \& Michaela Scholl

Research Report C011/17 


\section{Telemetry for migratory bats - a feasibility study}

Author(s): $\quad$ Sander Lagerveld, René Janssen, Jasper Manshanden, Anne-Jifke Haarsma, Simon de Vries, Robin Brabant \& Michaela Scholl

Publication date: 28 February 2017 
Sander Lagerveld, René Janssen, Jasper Manshanden, Anne-Jifke Haarsma, Simon de Vries, Robin Brabant \& Michaela Scholl, 2017. Telemetry for migratory bats - a feasibility study; Wageningen, Wageningen Marine Research (University \& Research Centre), Wageningen Marine Research report C011/17.

Keywords: migratory bats, offshore wind farms, telemetry, feasibility study.

Client: Rijkswaterstaat

Water, Verkeer en Leefomgeving

Postbus 2232, 3500 GE Utrecht

Zaaknummer 3117989/de Jong

This research was part of the WOZEP programme ('offshore wind ecological programme'), commissioned by Rijkswaterstaat and (co-)financed by the Ministry of Economic Affairs for the purposes of Policy Support Research Theme 'Wind op Zee' (Kennisbasisproject KB24-001-001).

Wageningen Marine Research is ISO 9001:2008 certified.

This report is free to download from https://doi.org/10.18174/417092

Wageningen Marine Research provides no printed copies of reports.

(C) 2017 Wageningen Marine Research Wageningen UR

Wageningen Marine Research The Management of Wageningen Marine Research is not responsible for resulting institute of Stichting Wageningen damage, as well as for damage resulting from the application of results or Research is registered in the Dutch research obtained by Wageningen Marine Research, its clients or any claims traderecord nr. 09098104, related to the application of information found within its research. This report BTW nr. NL 806511618 has been made on the request of the client and is wholly the client's property. This report may not be reproduced and/or published partially or in its entirety without the express written consent of the client. 


\section{Contents}

Summary

$\begin{array}{lll}1 & \text { Introduction } & 7\end{array}$

$\begin{array}{llr}1.1 & \text { Assignment } & 8\end{array}$

$\begin{array}{llr}1.2 & \text { The project team } & 8\end{array}$

$\begin{array}{lll}1.3 & \text { Acknowledgments } & 9\end{array}$

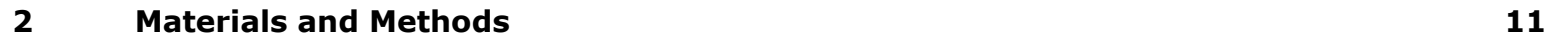

2.1 Selecting a suitable telemetry method 11

2.2 International standards and cooperation 12

$\begin{array}{ll}2.3 & \text { Performance of the equipment } \\ \end{array}$

2.3.1 Signal strength for 6 identical antennas 14

2.3.2 Signal strength for different angles between the transmitter and receiver $\quad 15$

2.3.3 Signal strength for different antennas $\quad 15$

2.3.4 Signal strength for different transmitter antenna lengths 16

2.3.5 Signal strength over land and over sea $\quad 16$

2.3.6 Signal strength with receivers at height $\quad 16$

2.3.7 Signal strength with receivers and transmitter at height $\quad 16$

$\begin{array}{ll}\text { 2.3.8 Signal strength with transmitter at height } & 17\end{array}$

$\begin{array}{ll}2.4 & \text { Tracking } \\ 2.5 & 17\end{array}$

$\begin{array}{lll}2.5 & \text { Trapping locations } & 20\end{array}$

$\begin{array}{llr}3 & \text { Results } & 21\end{array}$

$\begin{array}{lll}3.1 & \text { International standards and cooperation } & 21\end{array}$

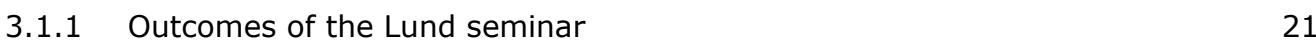

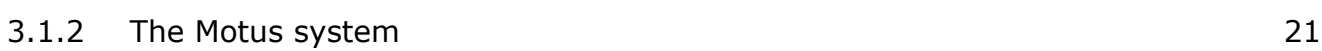

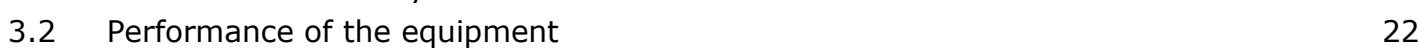

3.3.1 Signal strength for six identical antennas (test 1) 22

3.3.2 Signal strength at different angles (test 2) 23

3.3.3 Signal strength for different antennas (test 3) 25

3.3.4 Signal strength for different transmitter antenna lengths (test 4) 26

3.3.5 Signal strength over land and over sea (test 5) 26

3.3.6 Signal strength for receivers at height (test 6) 27

3.3.7 Signal strength for receivers at height and transmitter at height (test 7) $\quad 28$

3.3.8 Signal strength for transmitter at height (test 8) 28

3.3 Tracking $\quad 29$

$\begin{array}{lll}3.4 & \text { Trapping locations } & 33\end{array}$

$4 \quad$ Discussion and Conclusions $\quad 37$

$\begin{array}{lll}4.1 & \text { Technical infrastructure } & 37\end{array}$

\begin{tabular}{ll}
4.2 & International cooperation \\
\hline
\end{tabular}

$\begin{array}{lll}4.3 & \text { Trapping bats } & 38\end{array}$

$\begin{array}{llr}5 & \text { Recommendations } & 39\end{array}$

6 Quality Assurance $r$

$\begin{array}{lr}\text { References } & 43\end{array}$

$\begin{array}{lr}\text { Justification } & \mathbf{4 7}\end{array}$ 
Annex 1: Lund Conference 2016 


\section{Summary}

In recent years, research into the occurrence of bats at the Dutch North Sea has shown that there is regular seasonal migration over sea. However, so far, little is known about their migration ecology, the fatality risks at offshore wind turbines, and the number of individuals migrating over sea. Since the Dutch government wants to boost the further development of wind energy production in the southern North Sea, the Ministry of Economic Affairs commissioned to Rijkswaterstaat a Wind at Sea Ecological Programme (in Dutch: Wozep).

This study, as part of the Wozep-project Behaviour and Collision Risk of Bats (Bats_2), investigates how telemetry can be applied to gain insight into migratory movements of bats over land and over sea and individual bat behaviour near and in offshore wind farms.

To find out whether it is wise to continue and further develop telemetry research in the context of the Wozep programme, we first identified potential telemetry methods for small bats based on a desk study and selected the most promising method for the application of telemetry. Members of the team attended an international workshop on telemetry in Lund (Sweden) to gather practical technical knowledge, gain insight in data-management standards, and increase their international network. Several field tests were conducted to test the equipment and explore the possibilities of tracking. Finally, suitable locations for bat trapping in bat boxes and for the use of a Heligoland trap were identified.

There are several options to track bats with radio telemetry during their migration at the coast and over sea. However, for long-term monitoring of multiple individuals, establishing a grid of stationary receivers is the only feasible option.

Eight field tests were carried out to test the performance of the technical infrastructure. Each of the tests was unique and set up to test the signal strength/detection range for a certain type of antenna or a certain transmitter/receiver constellation. We showed that detections over at least $6 \mathrm{~km}$ are possible, and likely more than $10 \mathrm{~km}$ can be achieved. Precondition is that the receiving stations must be installed at high structures (lighthouses, buildings, masts) or hills, installing them a few meters off ground level will lead to detection ranges just over one $\mathrm{km}$.

Furthermore we explored the possibilities of calculating movement tracks with a setup of several receivers using different estimation methods. These experiments indicated that a relatively high accuracy (of c. $100 \mathrm{~m}$ ) can be reached estimating the location when signals of different receiving stations are combined. It is likely that the accuracy can be improved by estimating the bearings of the received signals based on the signal strength of different antennas. Even further improvement seems possible by assessing the (likely) flight route with a state-space model.

There are plenty of locations with bat boxes, especially in the province of Noord-Holland, where potentially hundreds of bats can be captured during migration stopovers, though it is not known how many of these are likely to be migrants. In addition, we identified four locations where actively migrating bats can potentially be captured with an Heligoland trap.

In conclusion, we are confident that telemetry can be successfully applied to study migratory movements of bats over land and over sea and individual bat behaviour near and in offshore wind farms.

Joining a wildlife tracking system like Motus (Canada) in order to enlarge the data collection, is highly recommended. Motus-members can get detections from both their own tags received by stations owned by other members, and from tags owned by other members if received by their own stations. 
In recent years, exploratory research into the occurrence of bats at the Dutch North Sea has shown that there is regular seasonal migration over sea of at least Nathusius' pipistrelle Pipistrellus nathusii but perhaps also of parti-coloured bat Vespertilio murinus and common noctule Nyctalus noctula (Boshamer \& Bekker 2008, Jonge Poerink et al. 2013, Lagerveld et al. 2014a, 2014b, 2015, Leopold et al. 2014).

Given the fact that the Dutch government wants to boost the further development and expansion of wind farms in the Dutch part of the southern North Sea in the coming years (SER agreement 2013), and the growing evidence that bats are vulnerable to barotrauma and collisions with wind turbines (e.g. Baerwald et al. 2008, Bach et al. 2014, Cryan et al. 2014), the Ministry of Economic Affairs commissioned to Rijkswaterstaat (RWS) a two-year monitoring programme in 2015 to establish a systematic inventory of the actual occurrence of bats over the North Sea. This study is currently being conducted in a project titled 'Research on distribution and behaviour of bats in the southern North Sea' (RWS case number 31103115). It aims at providing insight into bat movements over sea: which bat species do occur, in what numbers, at what times, and how does that relate to weather conditions? If there is a relationship, a risk assessment based on timing and weather conditions could be carried out. To determine the presence of bats, the study uses ultrasound bat detectors. However, translating 'call records' into numbers of individuals is not possible without understanding the underlying individual behavioural patterns of bats in offshore wind farms, e.g. stopover and recurrence behaviour. After all, when individuals spend an extended period of time around a wind turbine, their number in relation to the number of 'call records' will be lower than if individuals were passing through more rapidly.

In order to be able to make better estimates of the actual numbers of bats at sea, more research is needed into their migration behaviour in general as well as into their specific behaviour in (the vicinity of) offshore wind farms. At this moment it is not clear which proportion of the population migrates over sea and which proportions travels over land. Behavioural research at offshore wind farms is expected to provide the information required to estimate the number of (potential) fatalities and possibly to predict more accurately when and under what circumstances the fatality risk becomes so high that it would be better to stop the turbines. The more precise these predictions, the shorter the downtimes and revenue losses for the wind farm operators when compared with the situation where, due to lack of knowledge, wind turbines must be shut down for a longer period of time because of application of the compulsory precautionary principle.

When assessing the overall effect of offshore wind farms on migratory bats, three questions are central to the subject:

1) Which part of the population passing through the Netherlands migrates over sea, and which part over land?

2) Are bats migrating over sea attracted to offshore wind turbines, and if so, up to what distance?

3) What exactly is the behaviour of bats in the immediate vicinity of a wind turbine?

The overall effect of offshore wind farms on migratory bats will be largest when (1) a large proportion of the migrating bats moves over sea (2), migrating bats exhibit strong attraction to wind turbines, over a relatively large distance, and (3) individuals, exhibiting intensive flying/ foraging behaviour, spend much time in the vicinity of a wind turbine, thereby running a high risk of collision and/or barotrauma.

Studying bat behaviour therefore should be done at two different spatial scales: at the scale of an individual turbine and its immediate surroundings, and at the scale of a wind farm and beyond. The use of thermal cameras and bat detectors makes it possible to study the behaviour of bats near wind turbines in more detail, while telemetry appears to be a suitable technique to study the flight 
Telemetry can be applied in several ways (Kays et al. 2011). In its most basic form it is a method to register the presence or absence of bats, which for example can be used to determine stopover duration. However, telemetry also makes it possible to estimate the locations of tagged animals in time and reconstruct the actual path of movement. This can be done manually by making cross bearings of the received signals or automatically by a grid of fixed receivers. The latter option seems to be the best way to track migratory movements of bats (Janssen et al. 2016). More specifically, a grid of receivers offers the opportunity to investigate what bat migration over sea exactly looks like: do bats cross the sea as soon as possible, or - now that these artificial structures have appeared - do they fly from one (potentially insect-rich) wind turbine to another to opportunistically use them as foraging area? Can specific flyways be determined, and to what extent are bats attracted to wind farms? What is the relative importance of bat migration over sea compared to migration over land?

Eventually, the answers to these questions should - in combination with research into bat behaviour at individual wind turbines - provide a clearer picture of what is the overall effect of offshore wind farms on migratory bats over the North Sea.

Aim of this project is to investigate the feasibility of the application of telemetry in migration research of small bats (and possibly also birds). The results and conclusions should answer the question of whether it is wise to continue and further develop this type of research in the coming years, and which is the best way to implement telemetry research for migratory bats in the context of the Wozep programme (see section 1.1).

Therefore, the following activities were carried out in order to assess the technical feasibility of telemetry in bat research:

- $\quad$ Selection of the most promising method for tracking small bats (8-13 g) by telemetry

- $\quad$ Participating in an international workshop on automated telemetry

- Testing the performance of the selected equipment in the field, particularly regarding the detection range

- $\quad$ Assessing the possibility to determine locations by analysing signals from different receiver stations (tracking)

- $\quad$ Selection of potential trapping methods and locations for bats

\subsection{Assignment}

This present study titled Behaviour and Collision Risk of Bats (Bats_2), was commissioned by RWS and is part of the Wind op Zee Ecological Programma (Wozep; in English: Wind at Sea Ecological Programme), a multi-annual research programme initiated in view of the realisation of new offshore wind farms under the SER agreement (2013). The study comprises two parts: 1) Telemetry for migratory bats, and 2) Bat behaviour at wind turbines. The first part is reported here; the second part will be accounted for in a separate report.

\subsection{The project team}

The project team conducting this study consists of employees of Wageningen Marine Research (Sander Lagerveld, Jasper Manshanden, Michaela Scholl and Simon de Vries), Bionet Nature Research (René Janssen), Batweter (Anne-Jifke Haarsma), and the Royal Belgian Institute of Natural Sciences (RBINS; Robin Brabant).

Wageningen Marine Research has the project leadership, both substantive and managerial; Bionet Nature Research and Batweter are specialized in bat research and telemetry in particular; RBINS provided general ecological expertise. 


\subsection{Acknowledgments}

Many people contributed to this study. We received technical advice and assistance from Arne Andersson \& Sissel Sjöberg (Lund University), Liam Mcguire (Texas University), Jaclyn Smolinsky (University of Delaware), John Brzustowski, Stuart Mackenzie \& Phil Taylor (Motus), Heiko Schmaljohann \& Vera Brust (Vogelwarte Helgoland), Hans-Joachim Vogl (Telemetrie-Service Dessau), Martin Koch (University of Trier), Bengt Otto Christensen (Vargarda Radio AB) and Richard Joachims (ANJO Telemetrie).

Philipp Wevers (Biotrack) and Peter Sinnott (Lotek) advised us on the specifications of the transmitters and arranged quick supplies.

We would also like to thank Jan Boshamer, Jan Piet Bekker and Garry Bakker \& Niels de Zwarte (Bureau Stadsnatuur), to share their experiences with bat box research.

Last but not least, we thank Maarten Platteeuw and Marijke Warnas (both RWS) for their support and comments on earlier versions of this report. 


\section{Materials and Methods}

\subsection{Selecting a suitable telemetry method}

The project team identified potential telemetry methods for (small) bats based on an desk study. This, combined with the personal experience of the authors and several researchers we met during the workshop in Lund, led to the selection of the most promising method for the application of telemetry in small bat research within the Wozep programme.

The use of telemetry is a widespread method to follow the movements of animals. There are several devices on the market to track animals, such as GPS, geolocation loggers, acoustic and radio transmitters (www.lotek.com/www.biotrack.co.uk). For studying small bats and birds, GPS transmitters are still too big to send the locations to the researchers. GPS-loggers could be used, but need to get recovered by recapturing the tagged animals. Moreover, sunlight geolocators - as the name suggests - work with sunlight, which is not the best way to get location- information from nocturnally living bats. Acoustic transmitters typically work best underwater, thus leaving only radio telemetry as the potentially most appropriate technique now available for studying behaviour of small bats and birds, due to the small sizes of the transmitters and good transmission of the signals through air.

When using radio telemetry, the signals that are emitted by the tags can be detected with directional and omnidirectional antennas (Kenward 2007). The higher the frequency, the smaller the wavelength and the size of the antenna. The following equation is used to calculate the wavelength:

Wavelength $(\lambda$ in $\mathrm{m})=300(\mathrm{Mm} / \mathrm{s}$; i.e. speed of light) / Frequency (in Mhz)

The length of most antennas is half a wavelength, but also a full or a quarter wavelength are used.

For telemetry work, it is important that the antenna of a receiver has a large gain (so it is able to hear transmitters a long distance away). An antenna should have at least 6-9 Db gain (Kenward 2007). A Yagi antenna is a directional antenna, meaning that the back end (dipole) has a small gain and the front end has a large gain. This is expressed as the front to back ratio.

The signal strength does not only depend on the antenna and type of receiver. It is also influenced by the output of the transmitter (in uW), antenna length of the tag, orientation of tag antenna and environmental factors such as humidity, absorption, line of sight etc. (Taylor \& Lloyd 1978; Kays et al. 2011). In depth information about radio tracking can be found in the Manual for Wildlife Radio Tagging (Kenward 2007). Furthermore, O'Mara et al. (2014) summarize the knowledge of 50 years of radio tracking in bat research.

There are several ways to track animals during their day-to-day movements or during migration:

- manual radio-tracking from fixed locations in the landscape (Safi et al. 2007).

- manual radio-tracking while following the study object by car, speedboat (Kenward 2007) or plane (Holland et al. 2008; Körner et al. 2010, McCracken et al. 2016).

- $\quad$ a network of automatic autonomous receivers. For this, several systems can be applied (Kays et al. 2011; McGuire et al. 2011; Sjöberg et al. 2015, Rerucha et al. 2014, Deppe et al. 2015, Francis et al. 2016).

Janssen et al. (2016) concluded that a network of automated receivers would be the best option for studying bat migration over sea and at the coast. 
Assessing the location of a radio-tagged animal is done by bi- or triangulation, that is, finding the intersection of two or more received signals. An error polygon can be calculated around the point estimate, resulting in a measure of precision equivalent to the area of the polygon. The size and shape of the error polygon is determined by:

- the accuracy of the directional antenna

- the number of receivers that detect the signal

- the distance between the two receiving points

- the distance of the transmitter from the receiving points

- the angle of the transmitter from the receiving points.

- the sampling frequency (Swihart \& Slade 1985)

The most accurate estimate of an animal's location is obtained by receiving signals that are closest to the animal and at an angle of 90 degrees to each other (Springer 1979). To reduce the size of the error polygon, more bearings helps the animal's location estimated from the centre of the intersections.

Theoretically all frequencies between $30 \mathrm{MHz}$ and $500 \mathrm{MHz}$ can be used for the study of telemetry. Some frequencies are used for public services and communication and are therefore prohibited. Other frequencies are a known source for interference (high frequency noise). In remote areas, the use of spectrum is usually quite sparse so interference is often not a reason for concern. In urban areas, however, much of the spectrum can be in use. Especially streetlights, car alarms, etc. can be a nuisance. As a rule of thumb, one can state: high frequency have a low 'penetrating' power, but further range (suitable for open landscapes) lower frequencies have a more penetrating power, but less range (suitable for forests). The frequency used will have an impact on the longevity of the battery, very high frequencies need more energy to emit. The frequency used has an impact on the type of equipment used (especially on antennas used here, because they are adapted to one specific frequency). For radio telemetry in Europe $150 \mathrm{mHz}$ is the most commonly used frequency.

\subsection{International standards and cooperation}

We participated in an international workshop on telemetry in Lund (Sweden; see Annex 1) with the aim of gathering practical knowledge, e.g. on infrastructure, data-management, cooperation and the use of standards, as well as building up and expanding our international network.

\subsection{Performance of the equipment}

Telemetry requires transmitters and receivers. A receiver consists of an antenna and a processing unit. During the tests we used both omnidirectional and directional antennas and a SensorGnome (SG) processing unit with Funcube pro+ SDR dongles based on the provided part list and assembly instruction at www.SensorGnome.org. An alternative for this purpose could have been the Lotek SRX 800. However, since this receiver is not able to measure simultaneously at multiple channels, pulses from nanotags transmitters with pulse intervals of a few seconds could easily be missed when applied on fast moving animals like bats and birds, and therefore it was not deemed adequate for our purpose. Distances between the receiver antennas at the same mast were $75 \mathrm{~cm}$ to prevent interaction.

To test the detection range of the equipment several days were spent in the field. During all tests the antenna of the transmitter was held perpendicular to the antenna(s) of the receiver in order to optimise the signal strength, except during the last test when the antenna of the transmitter was held opposite to the walking direction. We glued the transmitter to the back a dead songbird, as advised by Heiko Schmaljohan and Phil Taylor, and then attached to the pole. This yields better results than attaching the transmitter directly to a wooden pole. 
A brief description of the tests conducted can be found in Table 2.1. with information on the type of experiment, the date and location, the actual weather conditions, and the equipment set up used. If not described otherwise, tags with $15 \mathrm{~cm}$ antenna length were used. The different geographical locations where the tests were carried out, are shown in Figure 2.1 (overview), 2.4 and 2.6 (detailed view).

Table 2.1 Overview of experiments carried out.

\begin{tabular}{|c|c|c|c|c|}
\hline No & Test & Date/Location & Weather conditions & Setup experiment \\
\hline 1 & $\begin{array}{l}\text { Signal strength for } 6 \text { identical } \\
\text { antennas }\end{array}$ & $\begin{array}{l}7 \text { Oct } 2016 \\
\text { WTTSW }\end{array}$ & Sunny, no wind & $\begin{array}{l}6 \text { identical directional antennas ( } 3 \text { antennas } \\
\text { per mast). Height of the mast } 6 \mathrm{~m} \text {. }\end{array}$ \\
\hline 2 & $\begin{array}{l}\text { Signal strength for different } \\
\text { angles between the receiver } \\
\text { antenna and transmitter }\end{array}$ & $\begin{array}{l}7 \text { Oct } 2016 \\
\text { WTTSW }\end{array}$ & Sunny, no wind & $\begin{array}{l}\text { Directional antenna on a } 6 \mathrm{~m} \text { mast. Rotated } \\
30,60,90,120,150 \& 180 \text { degrees } \\
\text { respectively. }\end{array}$ \\
\hline 3 & $\begin{array}{l}\text { Signal strength for different } \\
\text { antennas }\end{array}$ & $\begin{array}{l}7 \text { Oct } 2016 \\
\text { WTTSW }\end{array}$ & Sunny, no wind & $\begin{array}{l}3 \text { different antennas ( } 2 \text { directional \& } 1 \\
\text { omnidirectional) on different } 6 \mathrm{~m} \\
\text { Masts. }\end{array}$ \\
\hline 4 & $\begin{array}{l}\text { Signal strength for different } \\
\text { transmitter antenna lengths }\end{array}$ & $\begin{array}{l}7 \text { Oct } 2016 \\
\text { Zuidpier IJmuiden }\end{array}$ & $\begin{array}{l}\text { Cloudy, windy (6B) and } \\
\text { drizzle }\end{array}$ & $\begin{array}{l}\text { Directional antenna on a } 5 \mathrm{~m} \text { mast at the } \\
\text { Zuidpier. Signal strength measured over the } \\
\text { beach. Antenna lengths of the transmitter } \\
\text { respectively } 15 \text { and } 25 \mathrm{~cm} \text {. }\end{array}$ \\
\hline 5 & $\begin{array}{l}\text { Signal strength over land and } \\
\text { over sea }\end{array}$ & $\begin{array}{l}13 \text { Oct } 2016 \\
\text { Zuidpier IJmuiden }\end{array}$ & $\begin{array}{l}\text { Cloudy, windy (6B) and } \\
\text { drizzle }\end{array}$ & $\begin{array}{l}\text { Directional antenna on a } 5 \mathrm{~m} \text { mast at the } \\
\text { Zuidpier. Signal strength measured over sea. }\end{array}$ \\
\hline 6 & $\begin{array}{l}\text { Signal strength with receivers at } \\
\text { height }\end{array}$ & $\begin{array}{l}2 \text { Nov } 2016 \\
\text { Camperduin/Petten }\end{array}$ & $\begin{array}{l}\text { Windy }(6-7 \text { B) with frequent } \\
\text { severe showers. }\end{array}$ & $\begin{array}{l}\text { Receiver stations with } 3 \text { different antennas ( } 2 \\
\text { directional \& } 1 \text { omnidirectional) on top of } \\
\text { dune, tag } 30 \mathrm{~m} \text { lower at the dike. }\end{array}$ \\
\hline 7 & $\begin{array}{l}\text { Signal strength with receivers and } \\
\text { transmitter at height }\end{array}$ & $\begin{array}{l}2 \text { Nov } 2016 \\
\text { Camperduin/Petten }\end{array}$ & $\begin{array}{l}\text { Windy }(6-7 \text { B) with frequent } \\
\text { severe showers. }\end{array}$ & $\begin{array}{l}\text { Receiver stations with } 3 \text { different antennas ( } 2 \\
\text { directional \& } 1 \text { omnidirectional) on top of } \\
\text { dune, tag on other high dune. }\end{array}$ \\
\hline 8 & $\begin{array}{l}\text { Signal strength with transmitter } \\
\text { at height }\end{array}$ & $\begin{array}{l}9 \text { Nov } 2016 \\
\text { Camperduin/Petten }\end{array}$ & $\begin{array}{l}\text { Not much wind this day, } \\
\text { but drizzling regularly }\end{array}$ & $\begin{array}{l}\text { Tag on top of dune, receiver stations with } 3 \\
\text { different antennas ( } 2 \text { directional \& } 1 \\
\text { omnidirectional) were placed at the dike. }\end{array}$ \\
\hline 9 & $\begin{array}{l}\text { Tracking of } 2 \text { different routes of } \\
\text { tag }\end{array}$ & $\begin{array}{l}7 \text { Oct } 2016 \\
\text { WTTSW }\end{array}$ & Sunny, no wind & $\begin{array}{l}3 \text { masts, } 3 \text { identical antennas per mast on an } \\
\text { angle of } 60 \text { degrees. Two different routes } \\
\text { were completed. }\end{array}$ \\
\hline & \multicolumn{3}{|c|}{ WTTSW: Wind Turbine Test Site Wieringermeer. } & \\
\hline
\end{tabular}




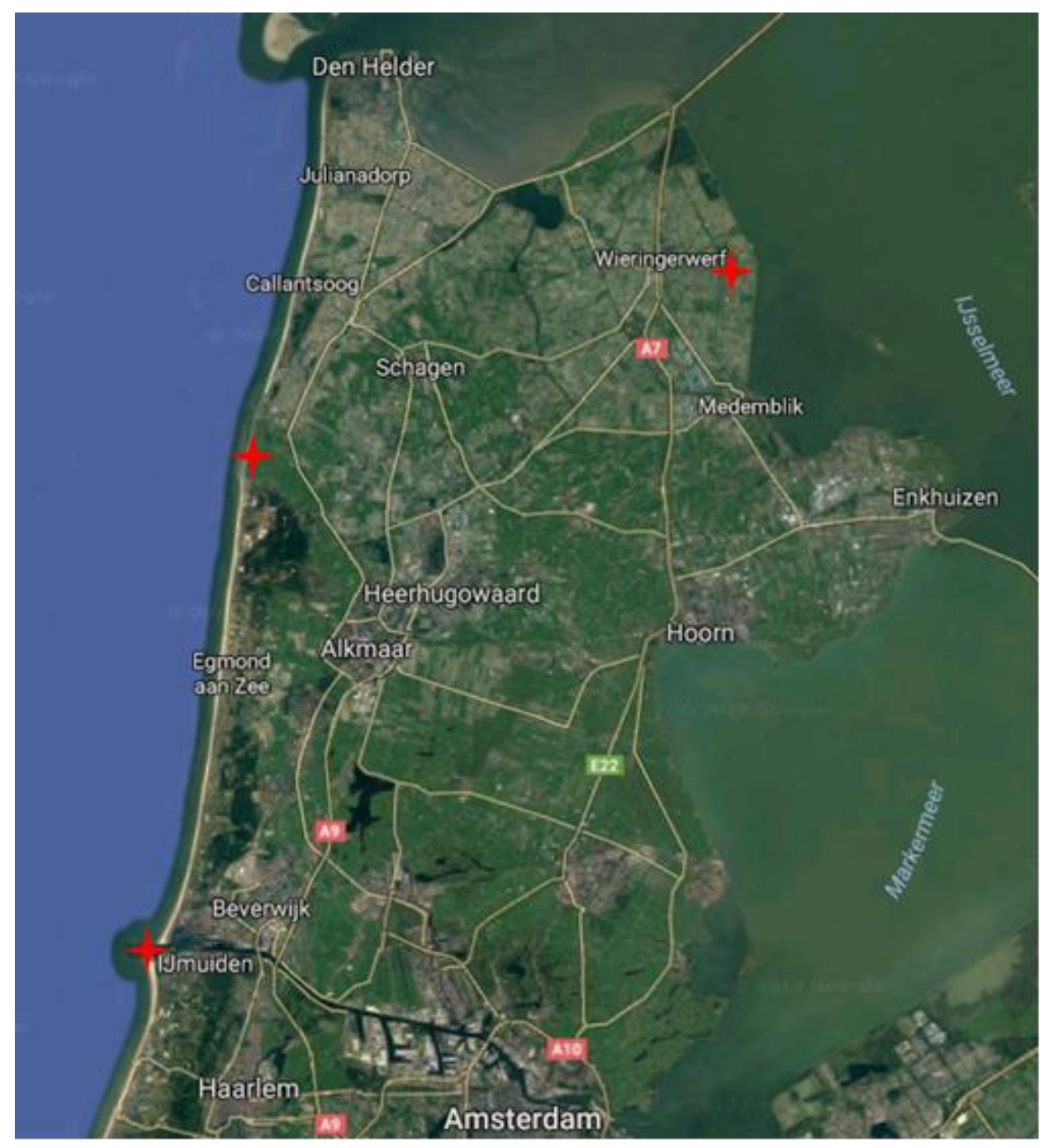

Figure 2.1: Map of the Province of Noord-Holland with the test sites (red stars): IJmuiden, Camperduin/Petten (between Callantsoog and Egmond aan Zee), and WTTSW (a few km east of Wieringerwerf).

\subsubsection{Signal strength for 6 identical antennas}

To assess differences amongst different antenna/receiver combinations we applied a test where we measured simultaneously the signal strength/detection range for 6 different 5-element Yagi antennas. The antennas were orientated in the same direction (Figure 2.2) at different heights $(4,5,5,25$ and 6 $\mathrm{m})$ at two different masts. The signal strength was measured at 50, 100, 200, 300, $400 \mathrm{~m}$ etc. until it could not be received anymore. 


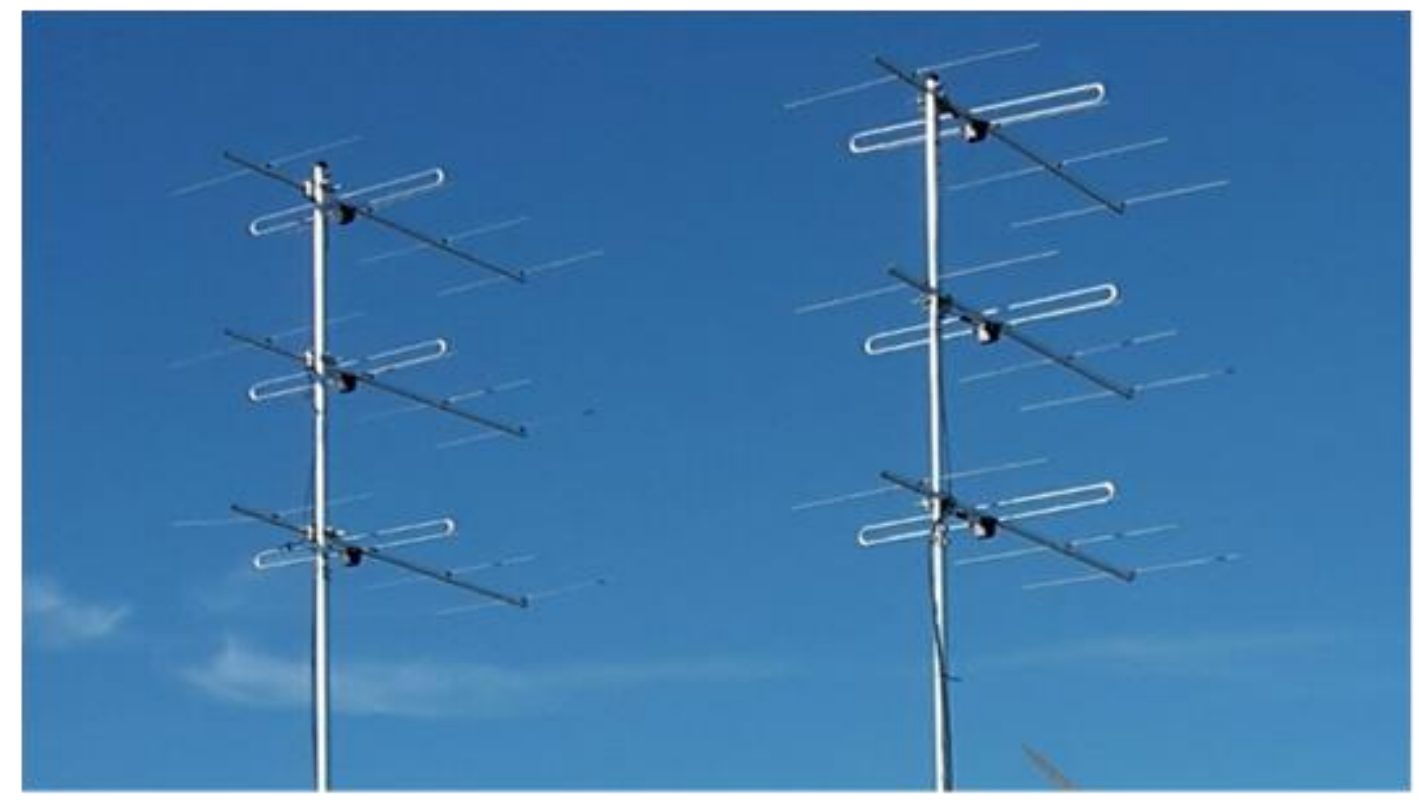

Figure 2.2: The measurement setup for comparing the signal strength for different antennas.

\subsubsection{Signal strength for different angles between the transmitter and receiver}

The sensitivity of directional antennas differs with the angle between the antenna and the transmitter. The highest sensitivity is at front (frontloop), but a backloop and sideloops are also present. To gain insight in the (field) characteristics of a 5-element Yagi we tested the circular characteristics with one of the upper antennas from the previous experiment. At first, the signal strength was measured when the antenna was orientated in the walking direction. After that, the measurements were repeated with a rotation angle of the antenna of $30,60,90,120,150$, and 180 degrees.

\subsubsection{Signal strength for different antennas}

For a comparison of different antennas we measured the signal strength at various distances for a 5element Yagi, 6-element Yagi and the omnidirectional Kathlein K51172 antenna (Figure 2.3).

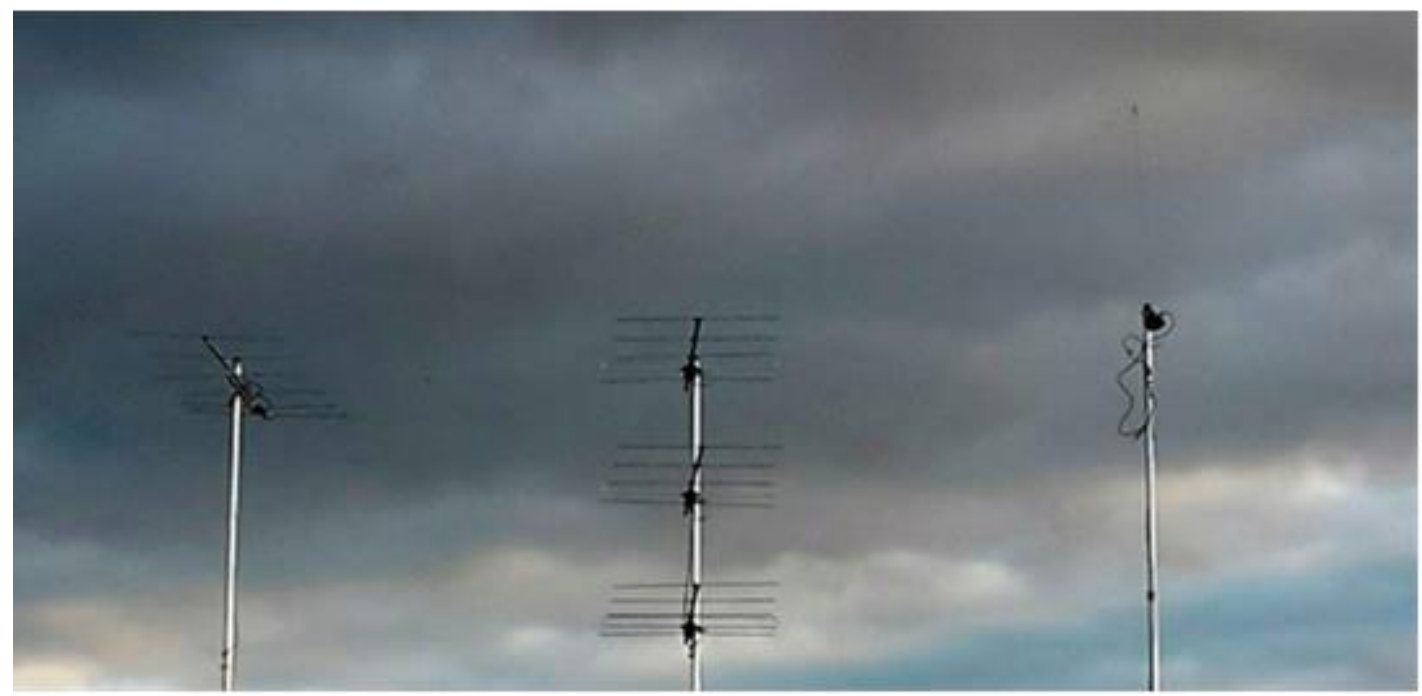

Figure 2.3: 6-element Yagi (left), 5-element Yagi (centre) and the omnidirectional antenna (right). In this experiment the signal of the upper 5-element Yagi was used. 


\subsubsection{Signal strength for different transmitter antenna lengths}

To assess the effect of the antenna length of the transmitter we measured the signal strength at various distances at the beach for different antenna lengths of 15 and $25 \mathrm{~cm}$, using one 5-element Yagi antenna (Figure 2.3).

\subsubsection{Signal strength over land and over sea}

For a comparison of the signal strength over land and over sea, the receiver was placed halfway the Zuidpier (Figure 2.4). The signal strength was measured over sea when walking along the shoreline using the transmitter with a $15 \mathrm{~cm}$-antenna. The results were compared with the results of the previous experiment.

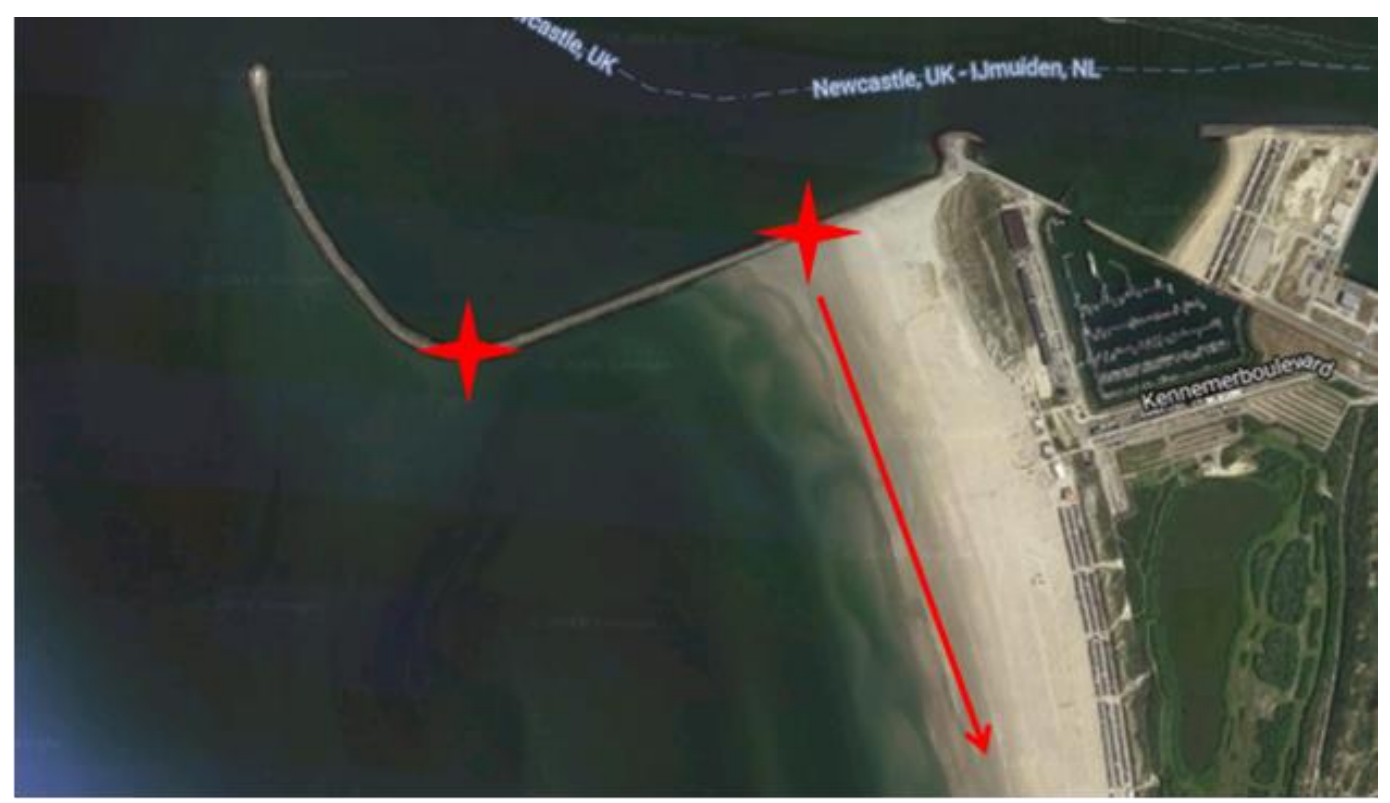

Figure 2.4: Location of the receivers (right experiment 4 and left experiment 5). The arrow indicates the track where the signal strength was measured at various locations.

\subsubsection{Signal strength with receivers at height}

To test the effect of height the receiver station was placed at a $40 \mathrm{~m}$ high dune and the transmitter at the $12 \mathrm{~m}$ high Hondsbossche Zeewering (the dike). The transmitter with $15 \mathrm{~cm}$-antenna used a $5 \mathrm{~s}-$ pulse interval. It was glued to the back of a dead Song Thrush Turdus philomelos (window kill), which was attached to a $4 \mathrm{~m}$ high pole (Figure 2.5). We used different antennas: the 5-element Yagi, 8element Yagi and the omnidirectional antenna Kathlein K51172 antenna.

\subsubsection{Signal strength with receivers and transmitter at height}

We used the same receivers as in the previous experiment and positioned the transmitter on a c. $25 \mathrm{~m}$ high dune at Petten (Figure 2.6), $5750 \mathrm{~m}$ from the receivers. 


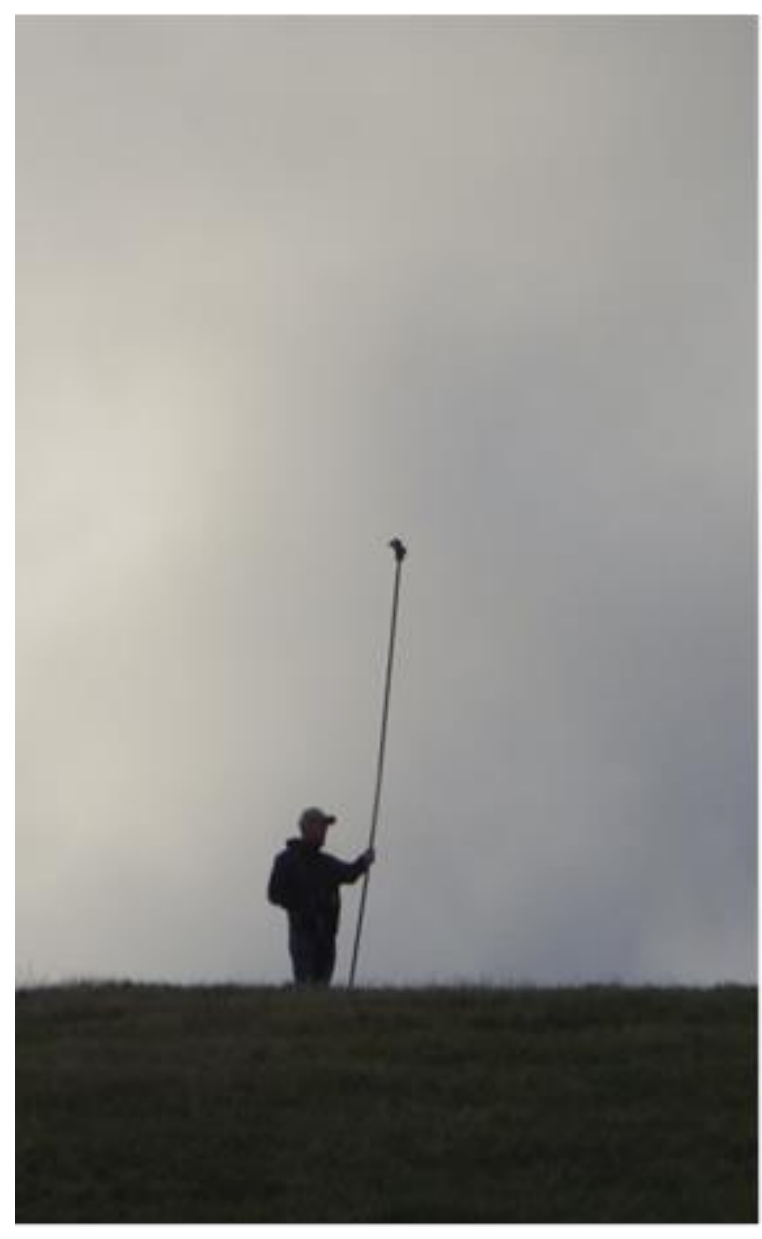

Figure 2.5: Walking at the Hondsbossche Zeewering with a dead tagged Song Thrush on a pole.

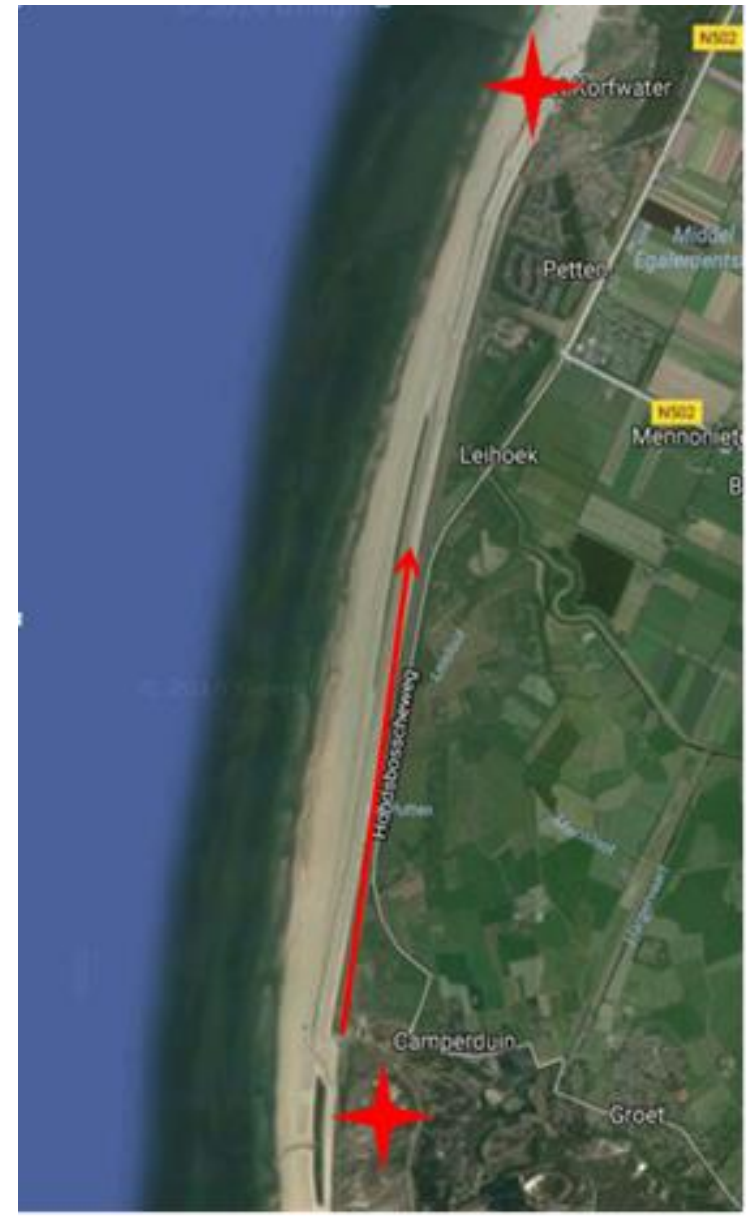

Figure 2.6: Location of the receivers at Camperduin and the location of the dune at Petten. The arrow indicates the track where the signal strength was measured at various distances.

\subsubsection{Signal strength with transmitter at height}

We repeated the previous experiment, but in reverse. This time the transmitter was put on the $4 \mathrm{~m}$ high pole at the same dune at Camperduin (Figure 2.5), and the receiver stations were placed at the dike to test the effect of a high transmitter. The Yagi's were placed at a height of c. $4 \mathrm{~m}$ in the mast and the omnidirectional antenna at c. $5 \mathrm{~m}$.

\section{$2.4 \quad$ Tracking}

There are several methods to analyse radio telemetry data for estimating locations by a grid of receivers (Kays et al. 2011):

- Assessing time differences in multiple received signals and calculate the location based on the travelling speed of the signals (MacCurdy et al. 2009)

- $\quad$ Received Signal Strength Indicator (RSSI; Kays et al. 2011): With this method, the location is calculated by signal strengths.

- Assessing the angle-of-arrival of multiple received signals and use bi-angulation or triangulation to estimate the location of the radio-tagged animal. 
During the first day in the field (7 October 2016) we also did an experiment to assess the tracking possibilities of the system used. Three different receiving stations were equipped with three identical (5 element) Yagi antennas which were rotated at an angle of 60 degrees relative to each other (Figure 2.7).

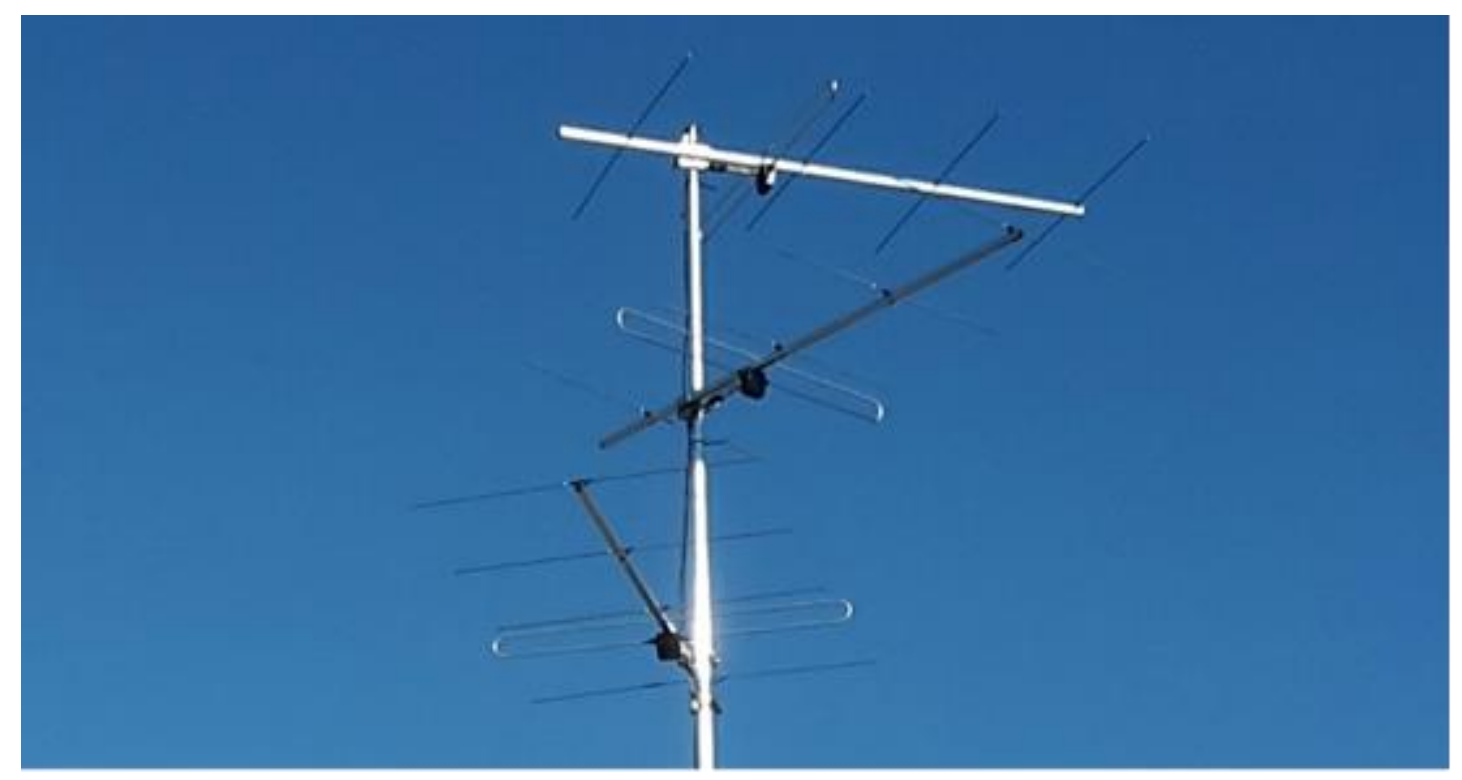

Figure 2.7: Yagi 5-element antennas rotated at an angle of 60 degrees relative to each other.

The receiver stations (SG1, SG2 and SG3) were positioned in a triangular setup (with distances respectively 428,436 and $473 \mathrm{~m}$ from each other), and we logged two GPS tracks at walking speed. One linear route including one bend from SG2 to SG3, and a more complicated route from SG3 back to SG2 via a zigzag near SG1 (Figures 2.8 and 2.9).

The orientations of the antennas at SG1 were at angles of 180, 240 and 300 degrees, receiver station SG2 at 300, 0 and 60 degrees, and receiver station SG3 with antennas orientated at 60, 120 and 180 degrees.

The estimation of the tracks was done as described by Smolinsky et al. (2013), using the algorithms maximum likelihood and average. To assess the accuracy of the estimated track we compared the GPS locations with the estimated locations. As the time stamps of the handheld GPS and the receiver signals are not equal, we used a subset of the estimated locations. We only used the data points if they were assessed within three seconds of the GPS location. 


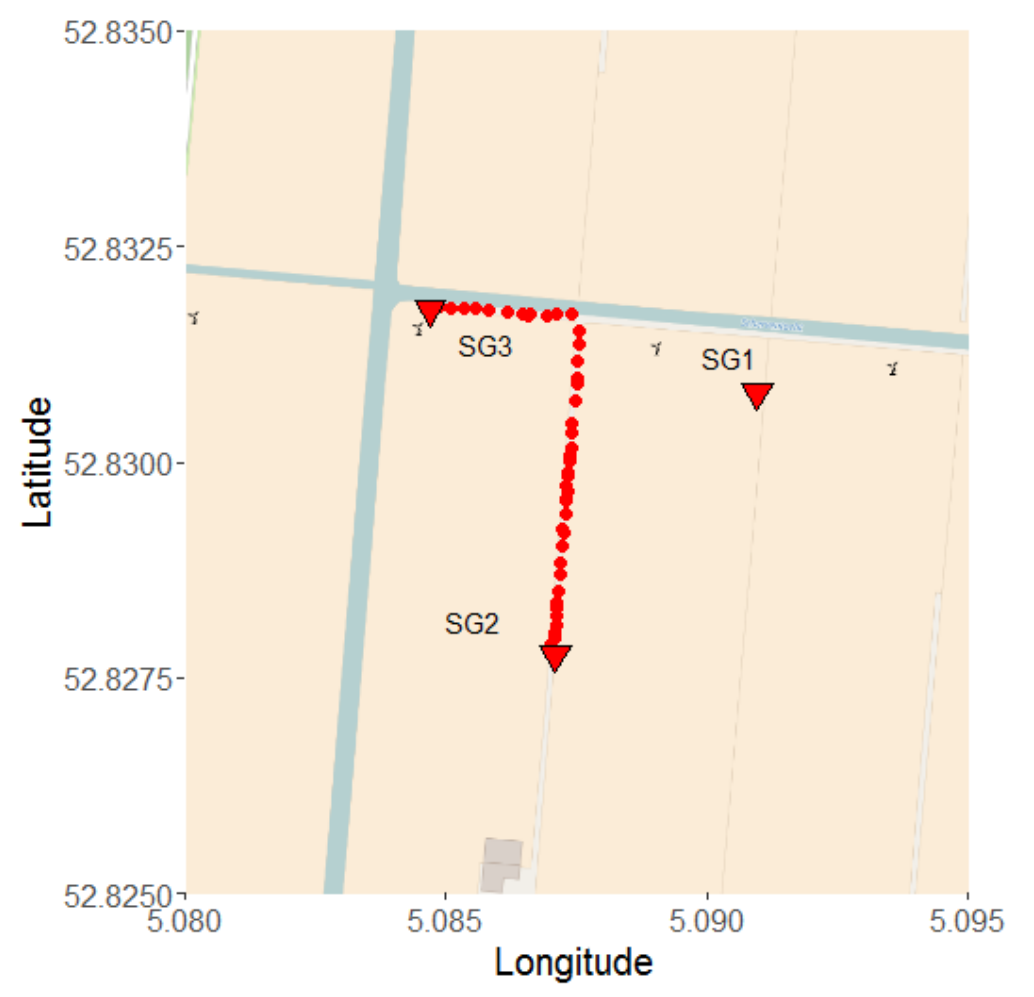

Figure 2.8: Walking track 1 from receiver station SG2 to SG3

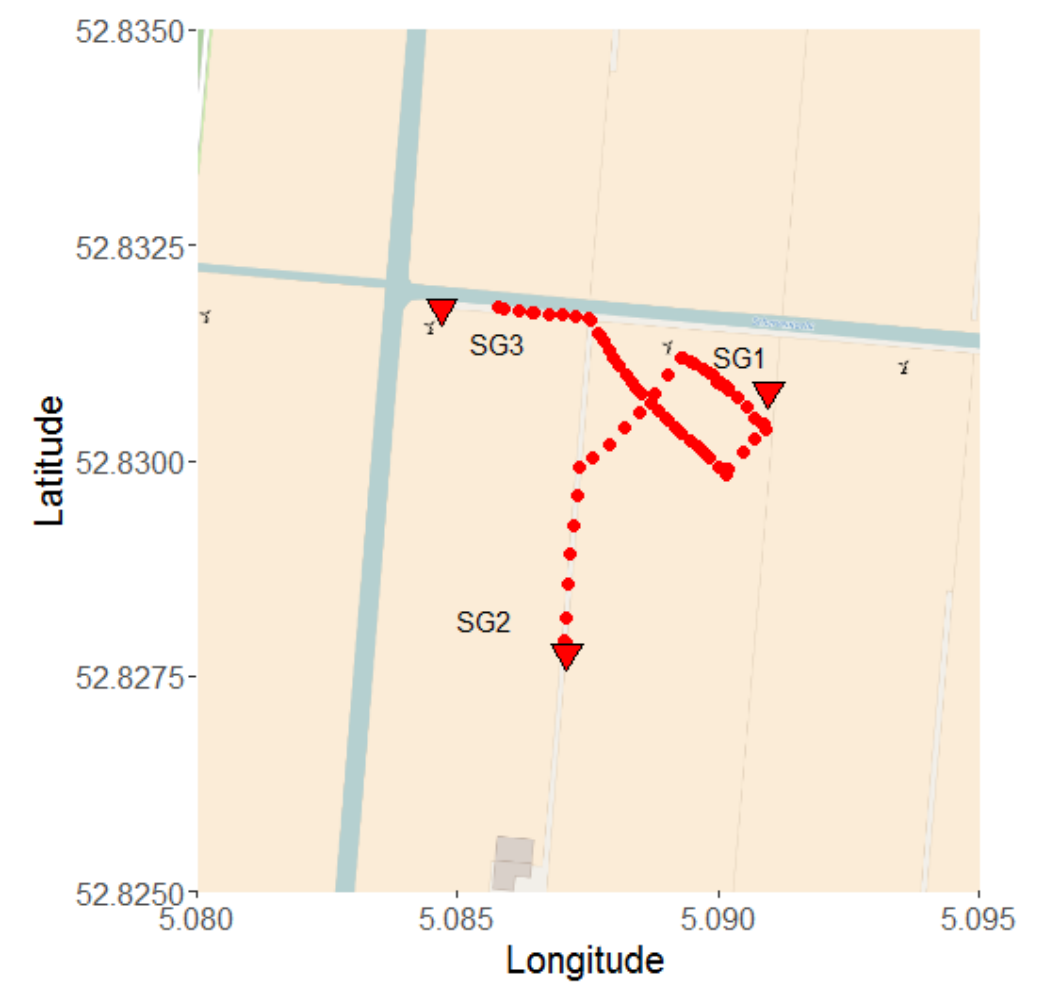

Figure 2.9: Walking track 2 from receiver station SG3 to SG2 via SG1. 


\section{$2.5 \quad$ Trapping locations}

The easiest way of trapping bats is to capture individuals which roost in bat boxes during migration stopovers. We assessed the locations where bat boxes are present and which can be used for this purpose.

Capturing actively migrating bats requires a Heligoland trap as other methods (mist nets, harp trap) are not feasible in coastal (open) landscapes (Janssen et al. 2016). We covered the coastline from Den Oever to IJmuiden and from the Maasvlakte to Vlissingen to identify potential locations for placing a Heligoland trap. 


\section{Results}

\subsection{International standards and cooperation}

As part of the agreed project activities, the possibilities were explored to align with methods favoured by other European groups involved in telemetry research. Below and in Annex 1 we provide further information on the seminar and Motus, a wildlife tracking system, presented in one of the sessions.

\subsubsection{Outcomes of the Lund seminar}

A representative of RWS and project team members of the Wageningen Marine Research, Bionet, and RBINS participated in the Conference on Automated Radio telemetry in Europe, held at the Centre for Animal Movement Research of the Lund University from 15-16 June 2016.

The most important outcomes of the meeting, when it comes to the application of telemetry for small bats and birds, are:

- The participants are confident that a European network of receivers can boost bird and bat migration research and both fundamental research (stopover ecology, migration performance, migration routes, etc.) and applied research (migration in relation to wind farms etc.) can benefit from this network.

- The participants wish to make a joint effort and establish such a network.

- Each researcher/research group should be part of Motus (see section 3.2.2) in order to be able to exchange data.

- A mailing list will be drawn up to be used for communication within the network.

- A working group was been established that will work out guidelines for founding a future European organization.

- National representatives were chosen.

- Each national representative or researcher/research group should apply for a permit to work on 150.100 MHz (for the time being; the process of applying for a joint European frequency will be initiated).

\subsubsection{The Motus system}

This section shortly describes the 'The Motus Wildlife Tracking System' (in short: Motus system or Motus). More detailed information can be found on the Motus-website ${ }^{1}$ and is described in Francis et al. (2016).

Motus is a system to track the movements of animals equipped with a radio transmitter (tag). It uses co-ordinated automated radio telemetry and comprises the physical and database infrastructure. Motus is linking the incoming signals from locations of the used tag by decoding the coded VHF tags. Motus hosts software, develops and distributes documentation, acts as central data repository and hosts data processed by users (and if appropriate: real-time monitoring data). Furthermore, it facilitates the sharing of data across projects (according to the principle of collaboration and reciprocity: you tagged a species, someone else detected it).

Researchers affix tags to animals that emit an unique identifier, which can be detected and recorded by automated receiving stations in the area. Technically spoken, thousands of tags can be

\footnotetext{
${ }^{1}$ www.motus.org
} 
simultaneously deployed and tracked by the system. Each telemetry station records signals from transmitter tags, either tags used by oneself or tags deployed by others.

The Motus system is hosted as a non-profit programme of Bird Studies Canada (BSC), a Canadian non-profit organisation, in partnership with Acadia University and other collaborating researchers and organizations. It is a fully open-source system and supported by several foundations.

When joining Motus, the first step requires to register the tags in an individual project environment. By doing so, the one who registers the tags, is acknowledged as the owner of the data. As part of the registering process, the project owner has to upload the recordings of his/her tag signals. After that, Motus issues a number by which it can identify the typical signal of the tag. All tower stations linked to Motus then help collecting data when receiving signals of the registered tags. So far, Motus only works with coded tags of Lotek (Canada) and Biotrack (UK).

To reduce the purchase costs of automated receivers and, by doing so, possibly boost the expansion of the receiver network, Motus developed a new type of automated receiver: the SensorGnome. This receiver works with a small computer (a BeagleBone or Rasperi Pi). Having additional USB-ports, it can process data of up to 6 radio-receivers, such as the Funcube dongle. Each antenna needs one radio receiver dongle. A GPS in the SensorGnome logs the location and makes sure that the UTC time is synchronized by 1 second (standard) or sub-millisecond (custom kit). The SensorGnome stores the recordings on a micro-SD card and can transfer the data via wifi or GMS-dongle. There are no disadvantages associated with the use of one dongle per antenna. On the contrary, it is a great advantage that one receiver can 'listen' simultaneously. By that, it is unlikely that a tagged species can pass without being noticed by the receivers, while the opportunity to make cross bearings increases.

Besides the SensorGnome, other receivers like the readily available Lotek SRX-800's are also compatible with the Motus network.

As mentioned before, Motus is part of a non-profit organisation. Its costs for starting up and maintaining the Motus system are covered from funds of several (Canadian) foundations. To cover for the variable costs of essential data services associated with the management and operation of the Motus database and the co-ordination of the network, each investigator/project owner who wants to join, is obliged to pay a 'tag-registration fee'. In addition, each investigator is obliged to pay a minimum annual deployment fee of c. 1000 EUR (1500 CAD). This accounts for the first 20 deployed tags, regardless of the total number of tags deployed, the number of receiving stations, or the number of projects created in the database. The tag fee and the minimum deployment fee are reviewed annually.

The tag fee is distributed evenly over the number of 'permanent' receiving stations deployed by an investigator or research group. According to Motus, a permanent station is one that is considered to be operational for at least 250 days/year. With this approach, Motus is trying to make up for its substantial investments in the installation and maintenance of receiving stations, while providing incentives for researchers to create and maintain their own stations, which eventually increases the temporal and geographic coverage of the network and the detection opportunities.

\subsection{Performance of the equipment}

\subsubsection{Signal strength for six identical antennas (test 1)}

The signal strength strongly depends on the distance between the receiving (5-element Yagi) antennadongle combination and the transmitter (Figure 3.1). It decreases significantly within $300 \mathrm{~m}$ and after that it levels off until the signal disappeared at approximately $1100 \mathrm{~m}$. The signal of the upper antennas (at $6 \mathrm{~m}$ ) is stronger than the middle $(5.25 \mathrm{~m})$ and lower antennas $(4.5 \mathrm{~m})$. There are no obvious differences between the antennas of each level. 


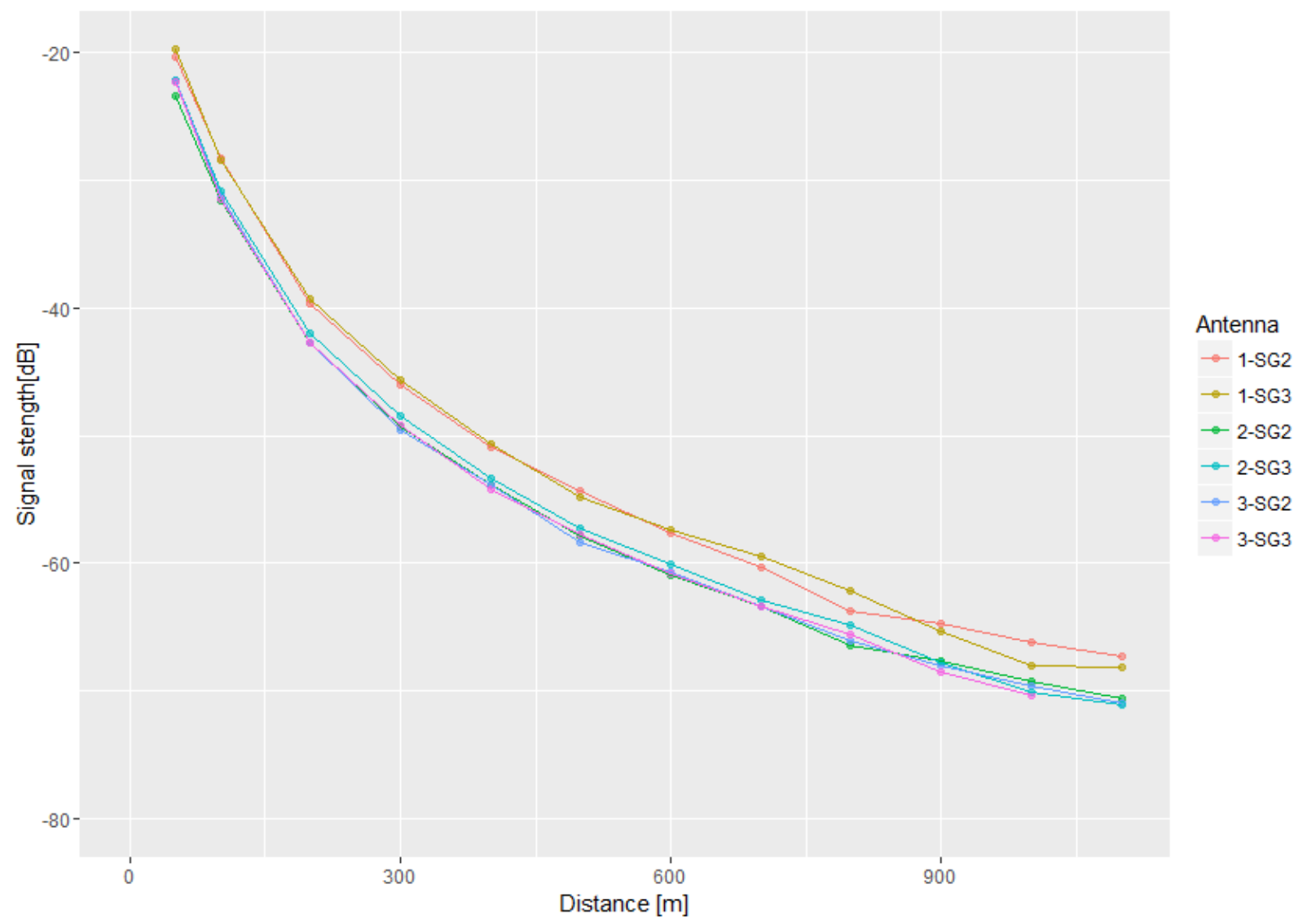

Figure 3.1: Average signal strength (based on 10 pulses at each location) as function of the distance for different 5-element Yagi antennas at 3 different heights (Antenna 1-SG2 and 1-SG3 at $6 \mathrm{~m}, 2-S G 2$ and 2-SG3 at 5,25 $\mathrm{m}$ and 3-SG2 and 3-SG3 at 4,5 m).

\subsubsection{Signal strength at different angles (test 2)}

The signal strength of one 5-element Yagi antenna at a height of $6 \mathrm{~m}$ was measured for different angles between the antenna and the transmitter at a distance of 50, 100, 200, 300, $400 \mathrm{~m}$ etc. until it could not be received any more (Figure 3.2). 
Angle 0 degrees

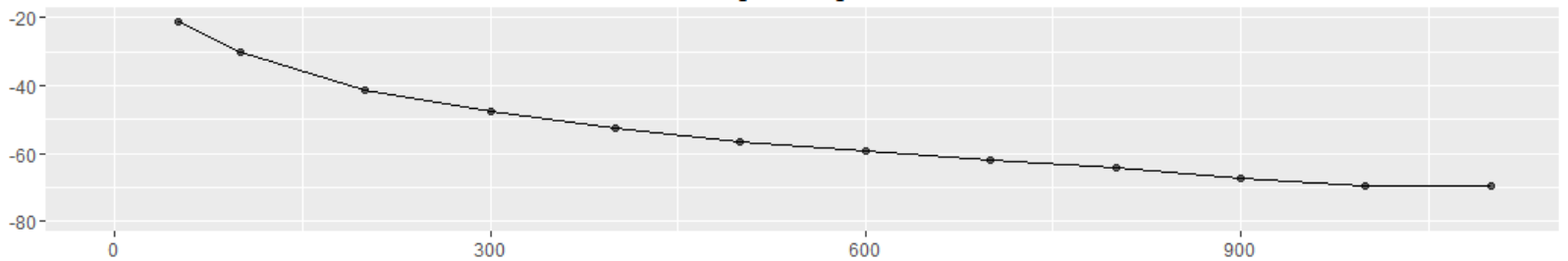

Angle 30 degrees

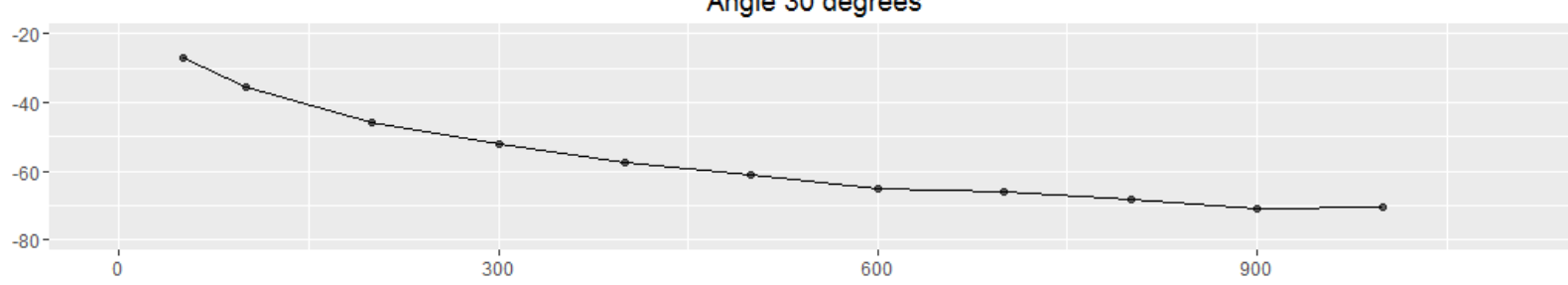

Angle 60 degrees

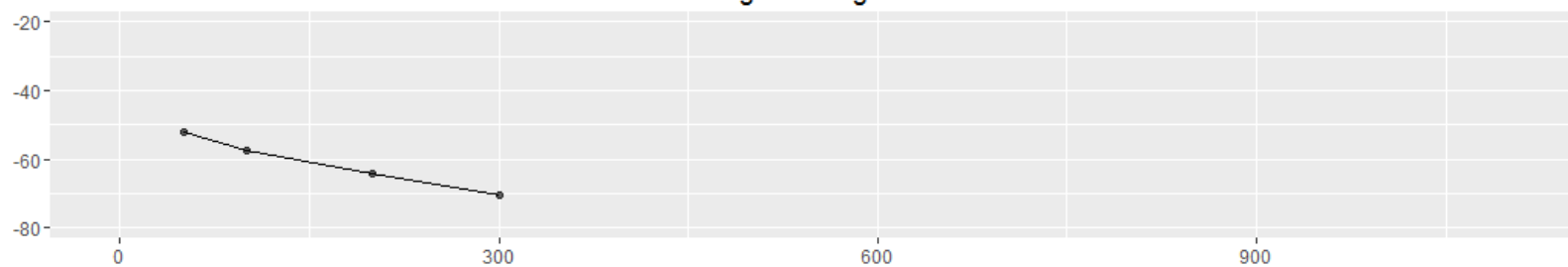

Angle 90 degrees

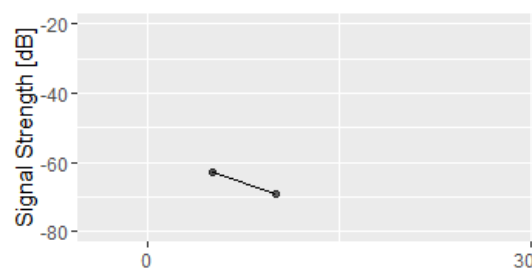

600

900

Angle 120 degrees

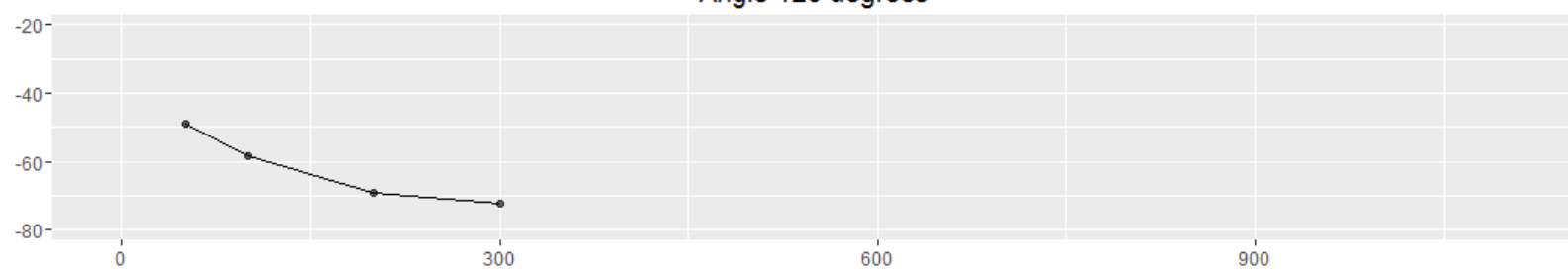

Angle 150 degrees
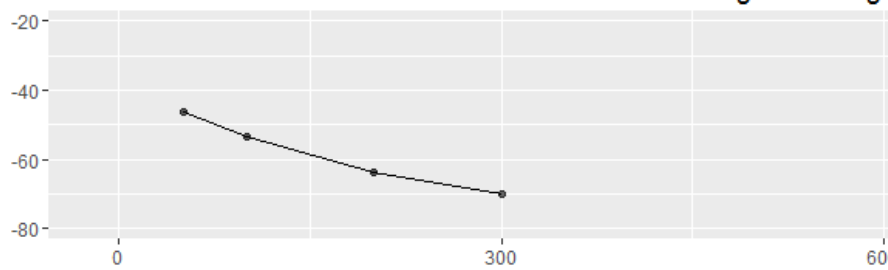

900

Angle 180 degrees

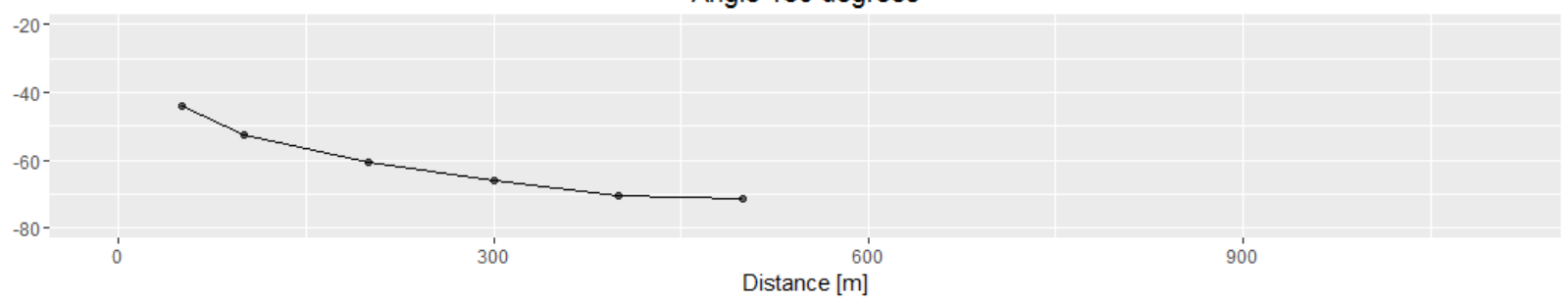

Figure 3.2: Average signal strength (based on 10 pulses at each location) as function of the distance for different angles between the transmitter and receiver using a 5-element Yagi antenna. 
The results show that the signal strength is not only affected by the distance between the receiver and the transmitter, but also highly dependent on the angle between the two. In a directional antenna like the 5-element Yagi the strongest signal is received between $0-30$ degrees (front loop). Small side loops are present at 60 and 120 degrees and a back loop at 150-180 degrees. Comparing the first and last results (at an angle of 0 and 180 degrees respectively), we confirmed the antenna used has a large enough front-back ratio for an accurate detection of flight direction.

\subsubsection{Signal strength for different antennas (test 3)}

Figure 3.3 shows the signal strength of two directional antennas (5-element Yagi), and 6-element Yagi) and an omnidirectional antenna (Kathlein K51172) as a function of the distance. The height of the antennas was $6 \mathrm{~m}$. The range of the omnidirectional antenna is very small in comparison with the directional antennas. Differences between the 5- and 6-element Yagi appear to be small, using them at a relatively low height.

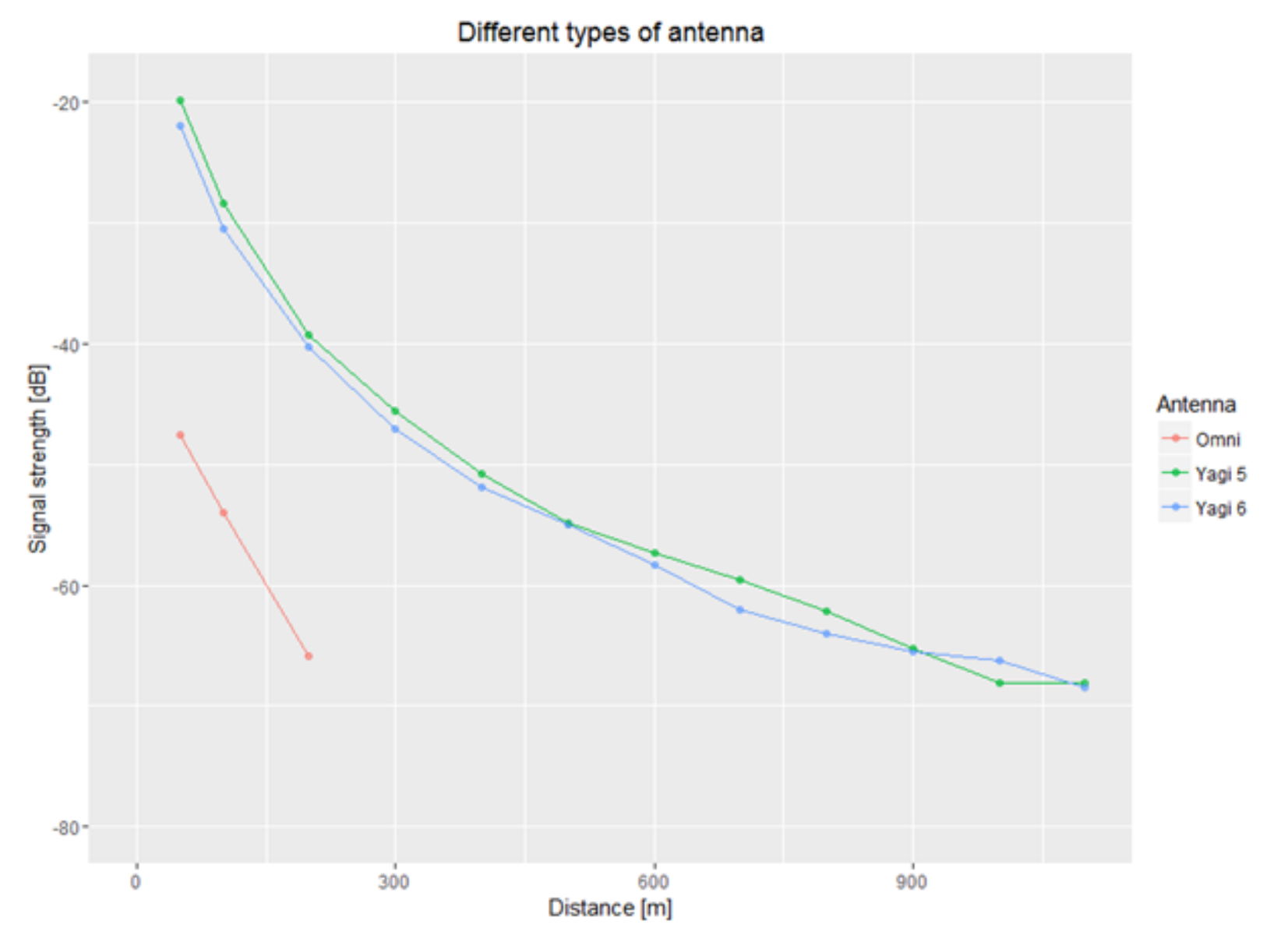

Figure 3.3: Average signal strength (based on 10 pulses at each location) as function of the distance for different antennas (5 element Yagi, 6 element Yagi and Omnidirectional antenna). 


\subsubsection{Signal strength for different transmitter antenna lengths (test 4)}

The signal strength of transmitters with different antenna lengths (15 and $25 \mathrm{~cm}$ ) was measured by a 5-element Yagi antenna at a distance of 100, 200, 400, 600, $800 \mathrm{~m}$ until it disappeared (Figure 3.4). The tests were performed consecutively. The detection range does not increase substantially with longer antenna lengths of the transmitter.

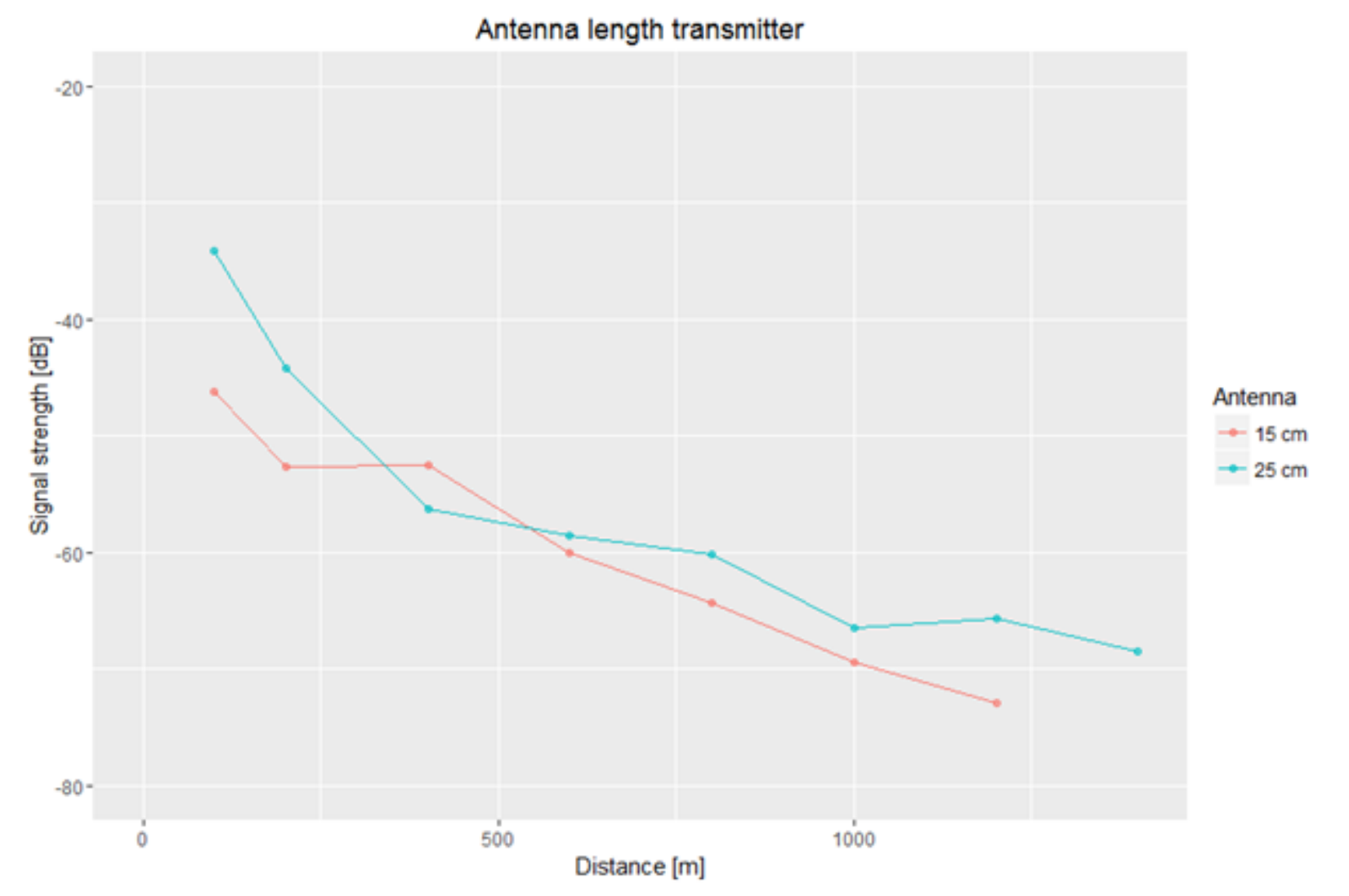

Figure 3.4: Average signal strength (based on 10 pulses at each location) as function of the distance for different antenna lengths of the transmitter.

\subsubsection{Signal strength over land and over sea (test 5)}

The signal strength of the transmitters with an antenna length of $15 \mathrm{~cm}$ was also measured over sea from the pier. Figure 3.5 shows the measured signal strength in comparison with the results over land from the previous experiment. The signal vanished after $800 \mathrm{~m}$, indicating that the detection range over sea (in windy conditions) may be less in comparison with land. 


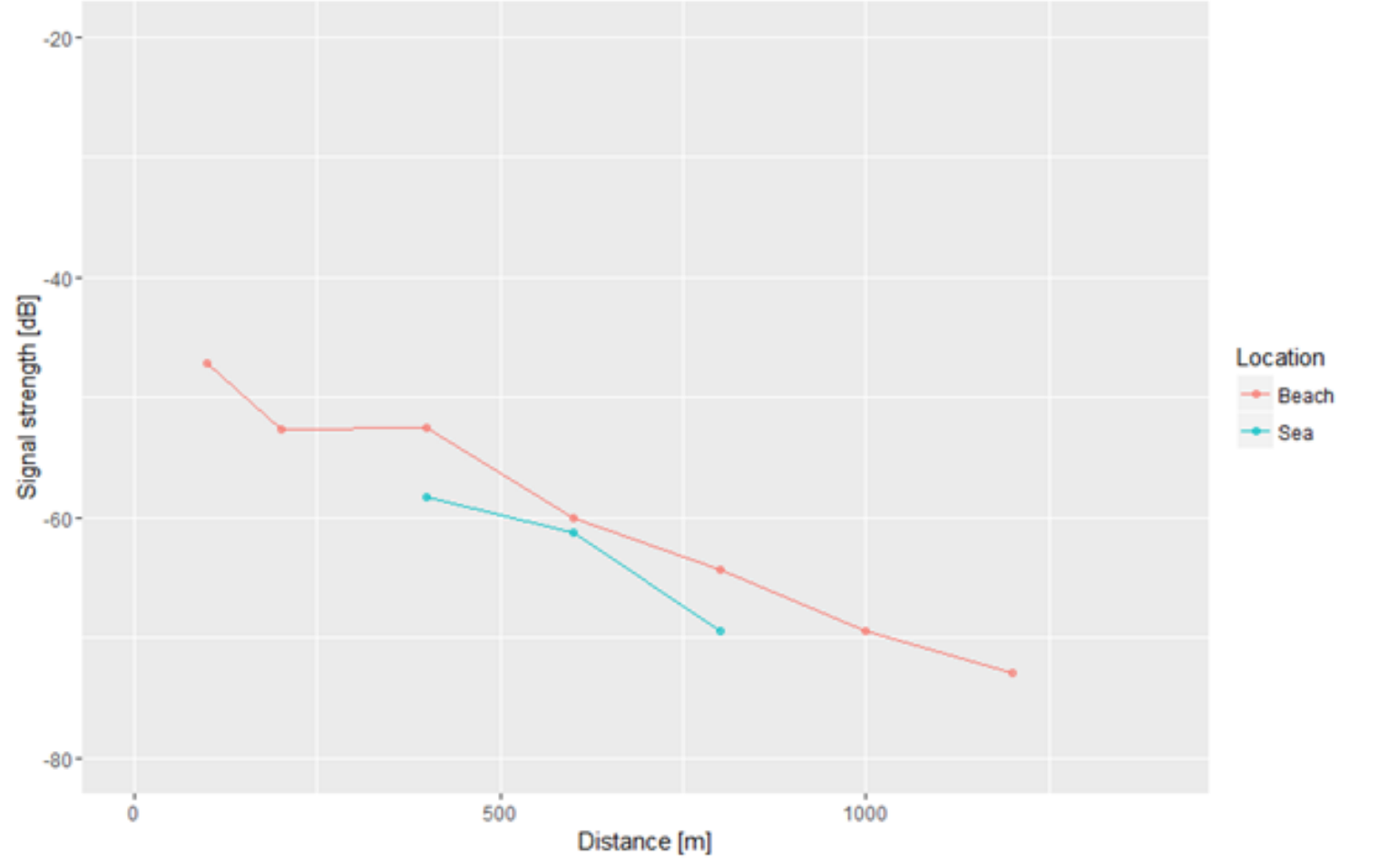

Figure 3.5: Average signal strength (based on 10 pulses at each location) as function of the distance for land and sea (in windy conditions)

\subsubsection{Signal strength for receivers at height (test 6)}

The sensitivity of the 8-element Yagi is much higher than the 5-element Yagi, resulting in a detection range of more than $3250 \mathrm{~m}$, which is $1000 \mathrm{~m}$ more than the 5-element Yagi (Figure 3.6). The range of the omnidirectional antenna was less than $500 \mathrm{~m}$.

Different types of antenna - high receiver

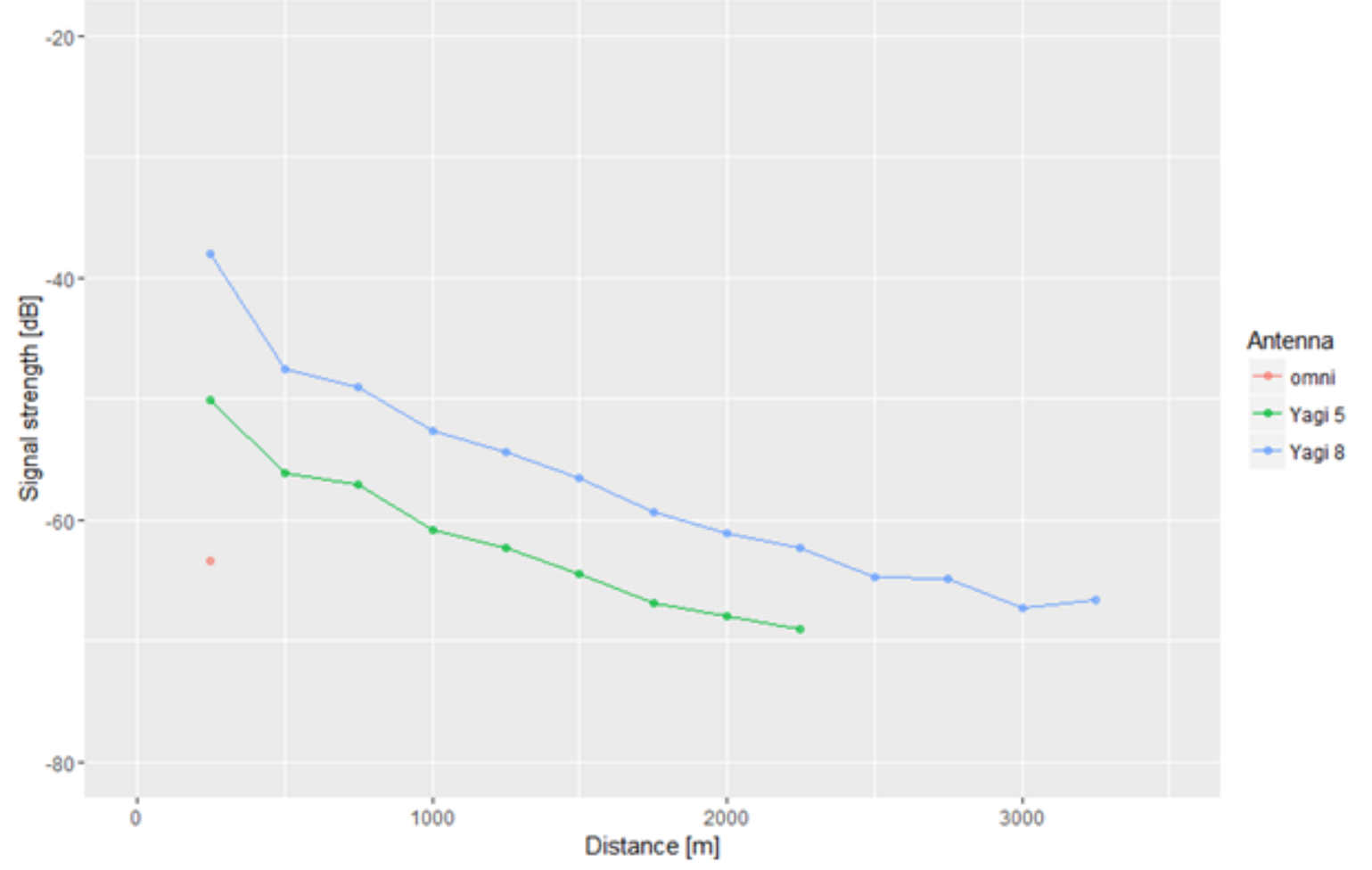

Figure 3.6: Average signal strength (based on 10 pulses at each location) as function of the distance for different antennas (Omnidirectional Kathlein K51172, 5-element Yagi and 8-element Yagi). 
It is also obvious that the detection range of the 5-element Yagi is extended by about $1000 \mathrm{~m}$ when it is installed at $40 \mathrm{~m}$ altitude compared to an installation height of only $6 \mathrm{~m}$ (experiment 3 ).

\subsubsection{Signal strength for receivers at height and transmitter at height (test 7)}

At a distance of $5750 \mathrm{~m}$ from the receiver we climbed a c. $25 \mathrm{~m}$ high dune at Petten (Figure 2.6) where we did receive the signal again from the transmitter on both the 5- and 8-element Yagi The 8element Yagi performed better in this situation than the 5-element Yagi (8-element: -61.79 and 5element: $-67.34 \mathrm{~dB}$ ). As detection stops around $-70 \mathrm{~dB}$, the actual detection range must have been larger, likely to be more than $7 \mathrm{~km}$. However, we could not measure this due to a lack of suitable dunes further away.

\subsubsection{Signal strength for transmitter at height (test 8)}

Figure 3.73 shows the results in the measurement setup where the transmitter (glued on the back of a dead bird on a pole) was placed at the top of a dune and the receivers were at the dike. It appears that the detection range of the omnidirectional antenna and the 5-element Yagi is comparable to the experiment 6, but the 8-element Yagi performs much worse.

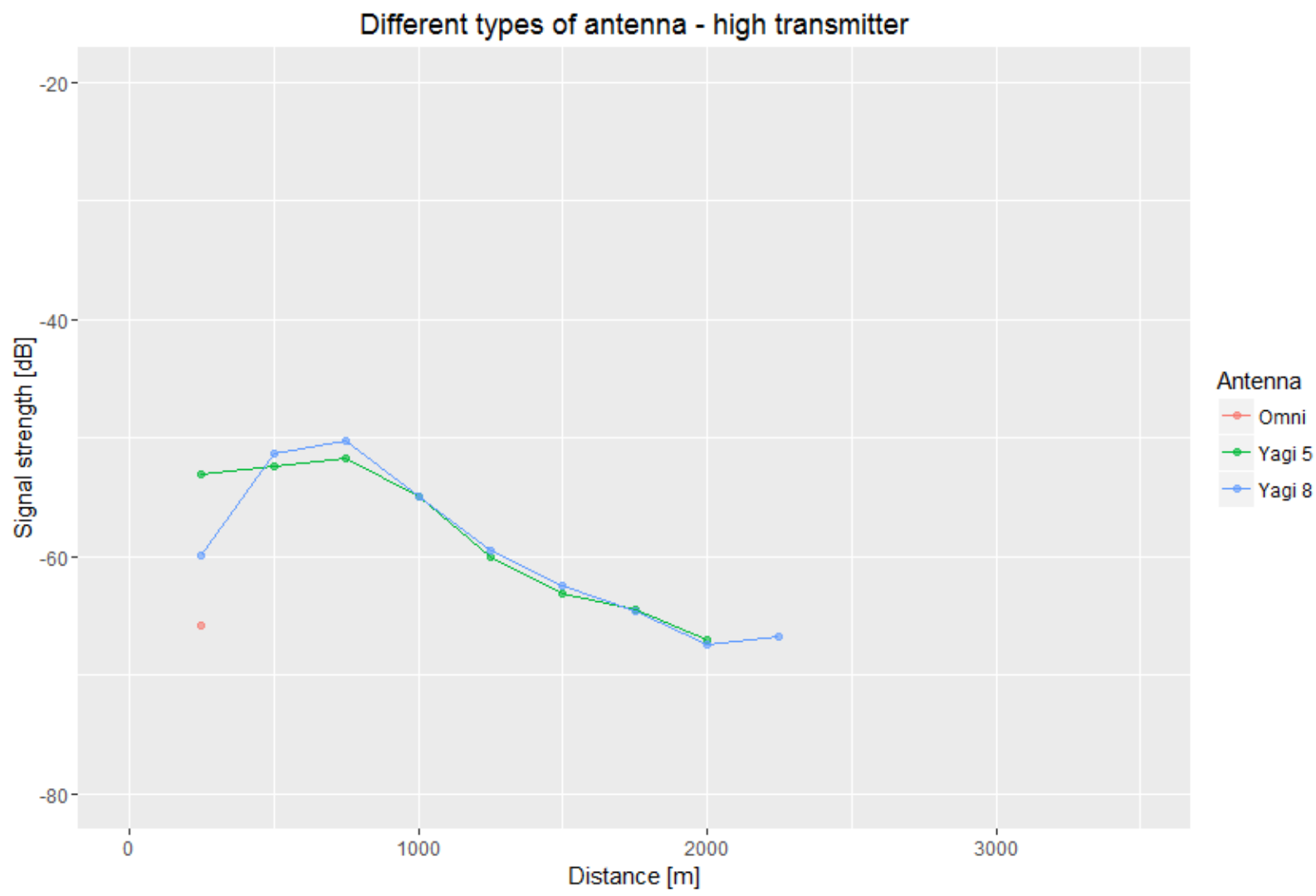

Figure 3.7: Average signal strength (based on 10 pulses at each location) as function of the distance for different antennas (Omnidirectional Kathlein K51172, 5-element Yagi and 8-element Yagi). 


\subsection{Tracking}

A tracking experiment was conducted in order to explore the possibilities of estimating the location of the transmitter based on the received signals of multiple receiver stations. Figures 3.8 and 3.9 show the results of the estimation of the tracks using the maximum likelihood algorithm in comparison with the walking tracks measured by GPS. The receiver stations SG1, SG2 \& GG3, each equipped with three identical 5 element Yagi antennas, are also indicated.

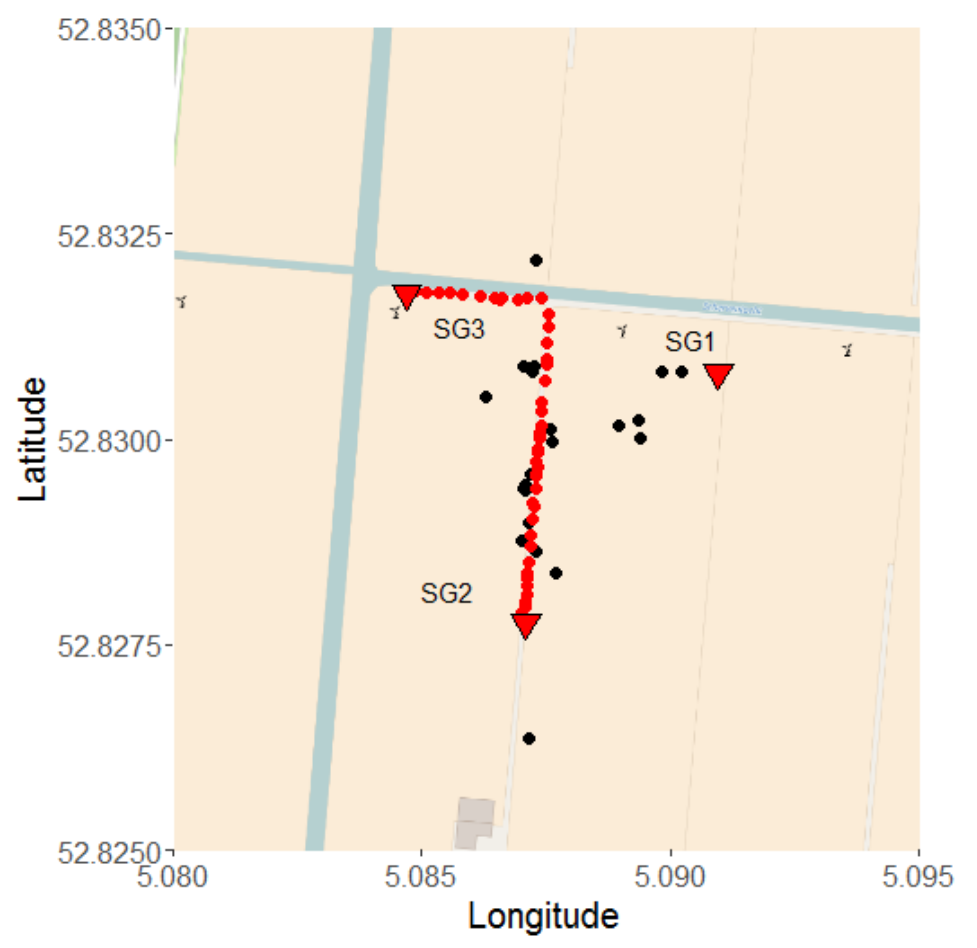

Figure 3.8: Estimated positions based on the maximum likelihood algorithm (black dots) and actual walking track 1 (red dots).

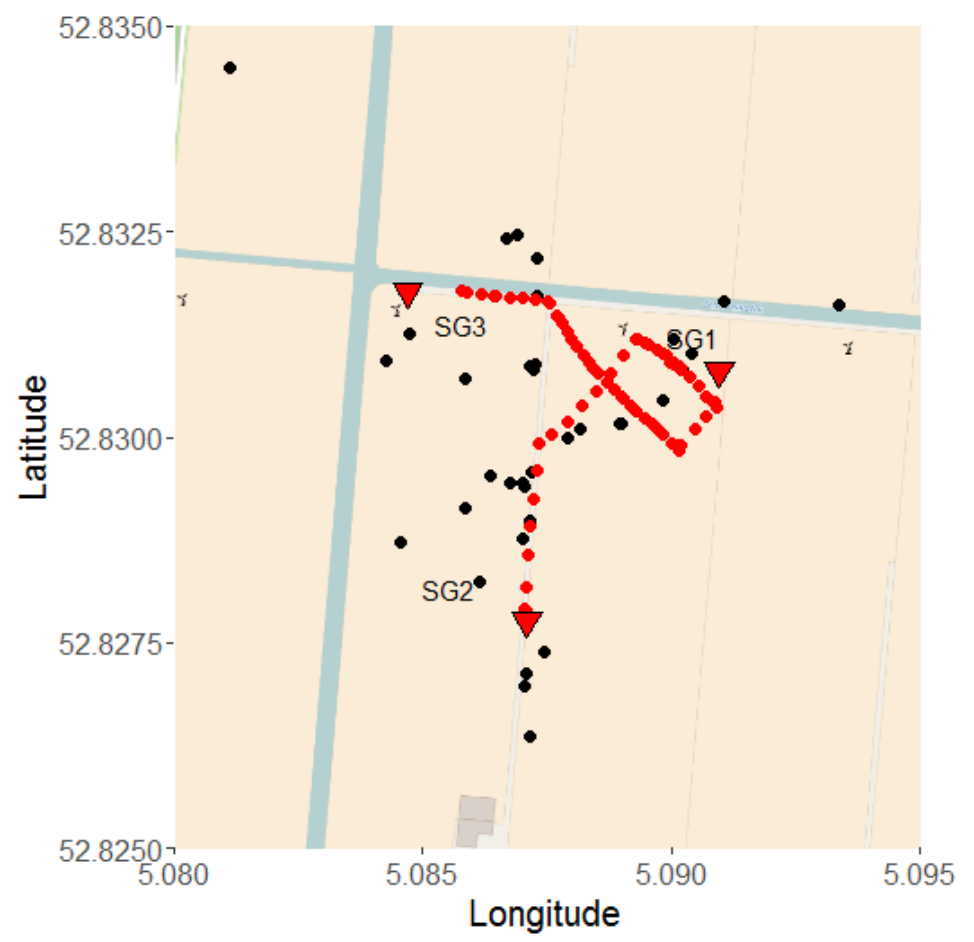

Figure 3.9: Estimated positions based on the maximum likelihood algorithm (black dots) and actual walking track 2 (red dots). 
Figures 3.10 and 3.11 show the results of the estimation of the tracks using the average algorithm in comparison with the walking tracks measured by GPS.

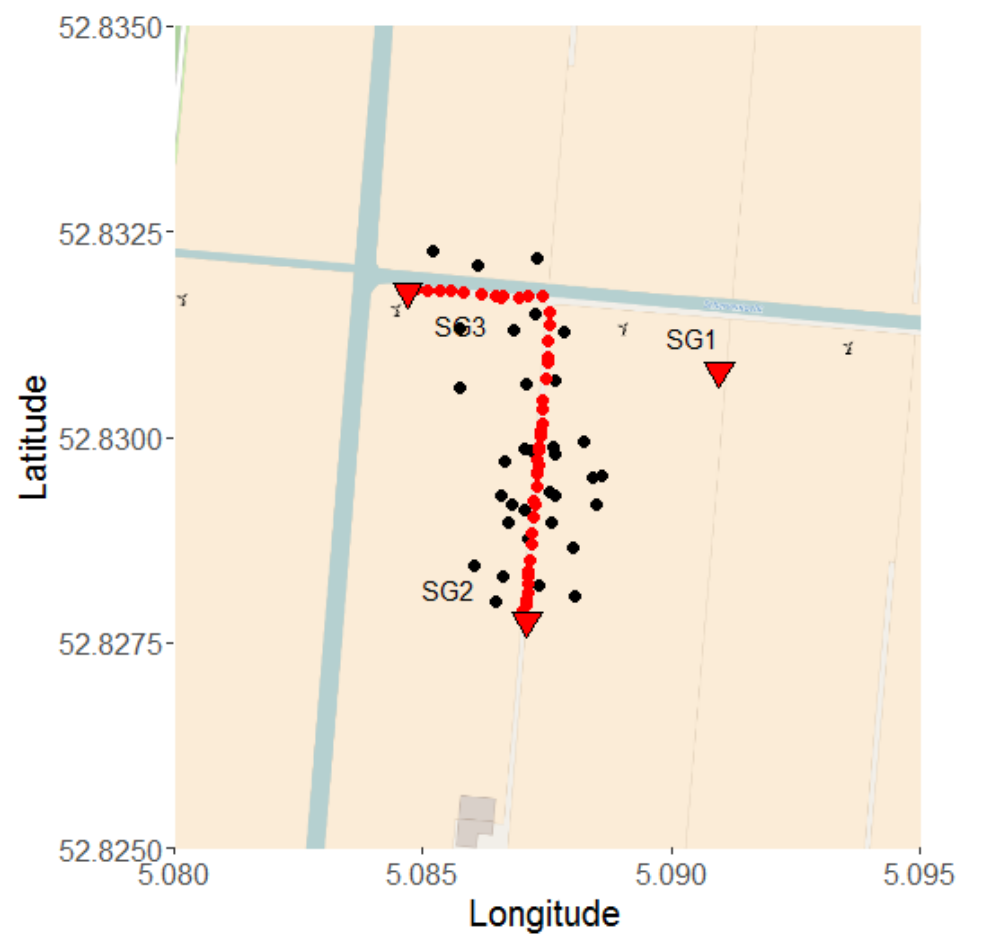

Figure 3.10: Estimated positions based on the average algorithm (black dots) and actual walking track 1 (red dots).

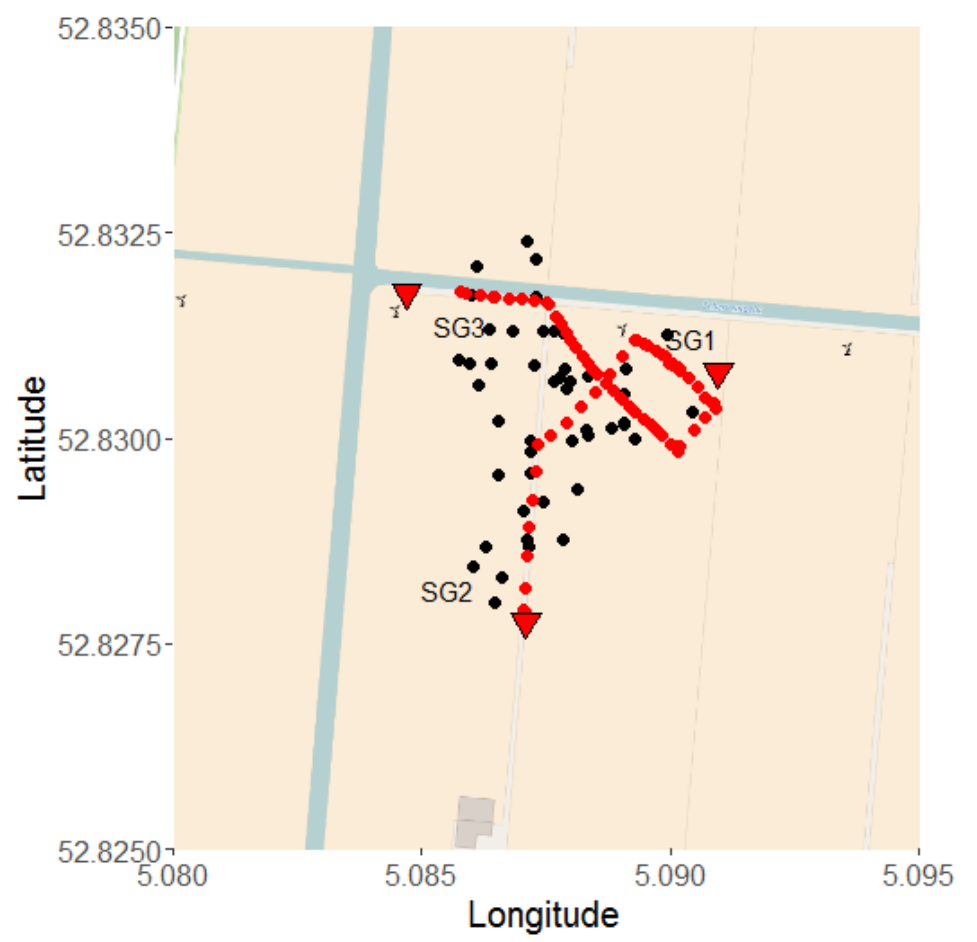

Figure 3.11: Estimated positions based on the average algorithm (black dots) and actual walking track 2 (red dots). 
In order to get an impression of the accuracy of the estimated locations, we calculated the distance (in meters) between the estimated location with the corresponding actual location (as measured by GPS). The results for the maximum likelihood algorithm are shown in figure 3.12 (track 1) and figure 3.13 (track 2), and for the average algorithm figure 3.14 (track 1) and figure 3.15 (track 2). The average error in the (distance between estimated location and actual location) was respectively 118, 192, 104 $\& 119 \mathrm{~m}$, showing that the average algorithm produces more accurate results than the maximum likelihood algorithm in this experimental setup.

\section{MLE of track 1}

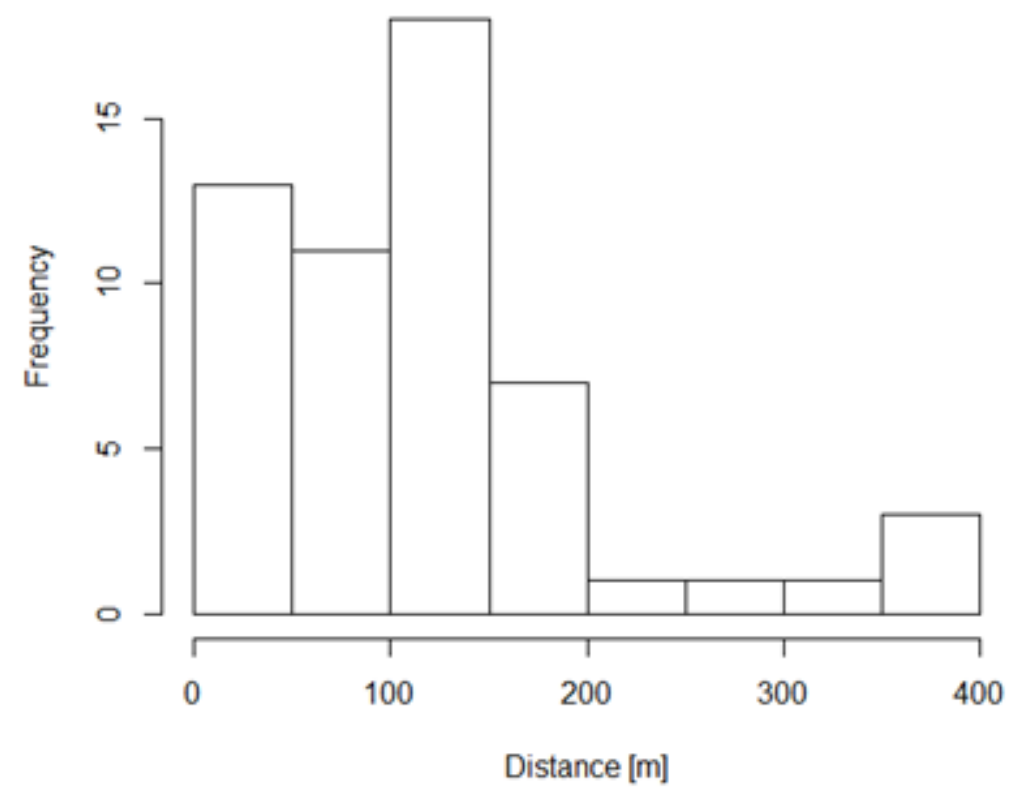

Figure 3.12: Histogram of the difference between actual GPS location and estimated location by telemetry based on the maximum likelihood algorithm for track 1 . The mean difference was $118 \mathrm{~m}$. 
MLE of track 2

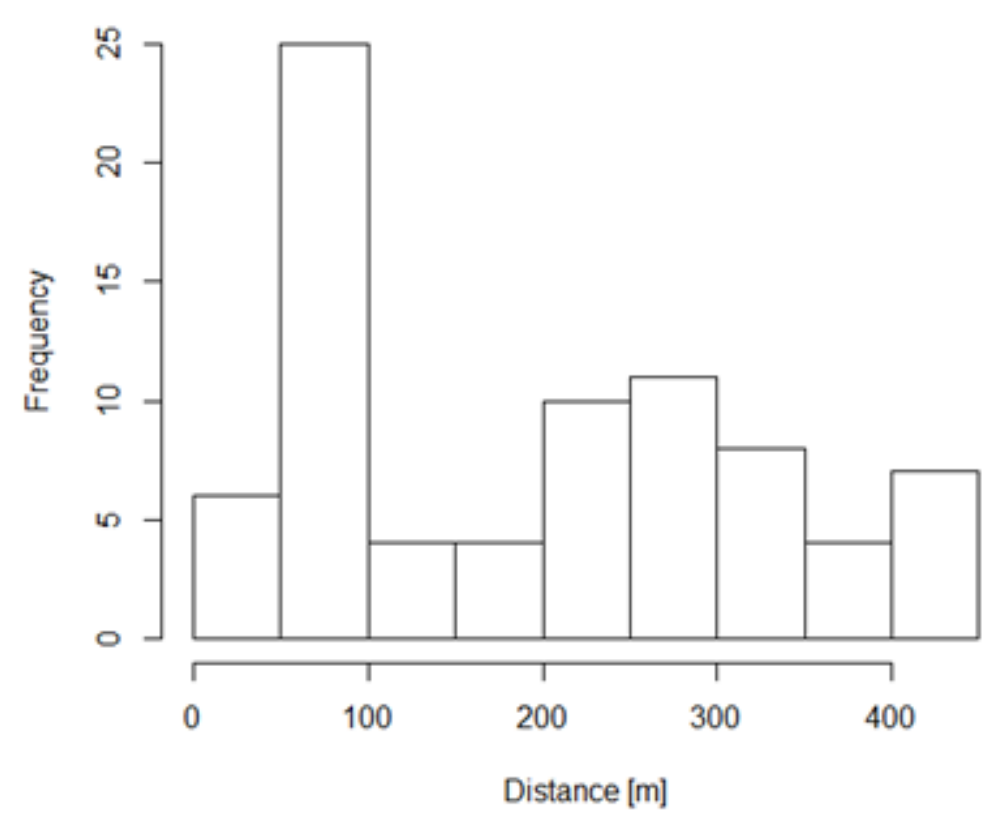

Figure 3.13: Histogram of the difference between actual GPS location and estimated location by telemetry based on the maximum likelihood algorithm for track 2. The mean difference was $192 \mathrm{~m}$.

\section{Average of track 1}

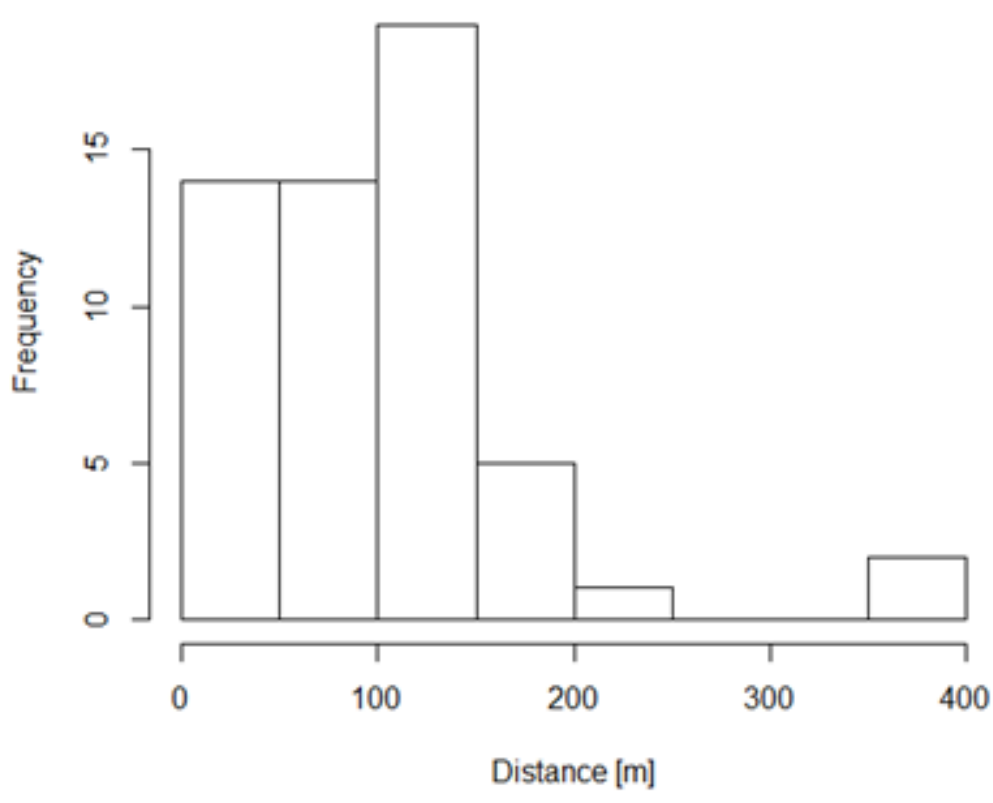

Figure 3.14: Histogram of the difference between actual GPS location and estimated location by telemetry based on the average algorithm for track 2. The mean difference was $104 \mathrm{~m}$. 


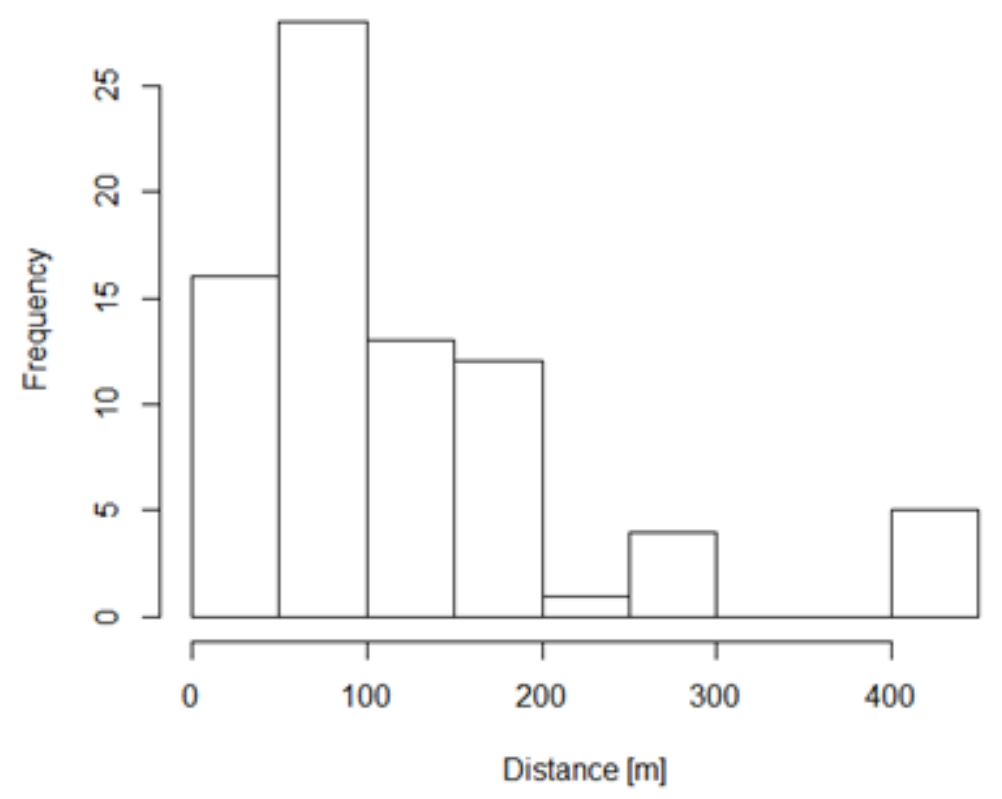

Figure 3.15: Histogram of the difference between actual GPS location and estimated location by telemetry based on the average algorithm for track 2. The mean difference was $119 \mathrm{~m}$.

\subsection{Trapping locations}

Bats can easily be captured in bat boxes. Especially in the northern part of Noord-Holland there are approximately 250 bat boxes owned by a local group of volunteers. The locations of the bat boxes can be found at http://vleermuizentellen.nl/kaarten/ruige-dwergvleermuis.html.

Another possibility to capture bats is using a Heligoland trap (Janssen et al. 2016). Several locations were identified where coastal bat migration can be expected and where a Heligoland trap can be physically set up, assuming a trap with similar dimensions as the mobile trap at Pape station, Latvia (Figure 3.16). 


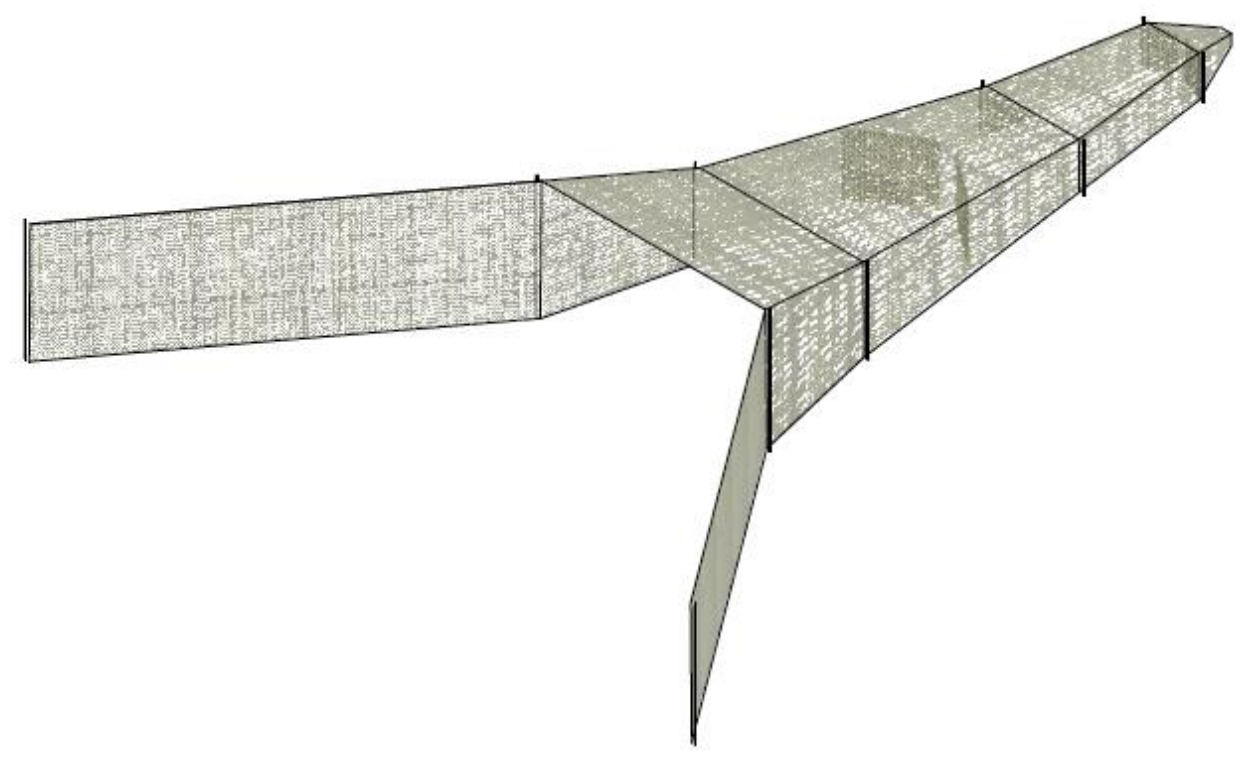

Figure 3.16: Replica of the mobile Heligoland trap from Pape station (Latvia). The dimensions of this trap are approximately $30 \times 45 \times 6 \mathrm{~m}$.

Previous studies have shown that many bats migrate along the Afsluitdijk (Kapteyn 1995, pers. obs. AJH, RJ, SL, unpublished data Rijkswaterstaat) and to a lesser extent along the coast (Lagerveld et al. 2015, Janssen et al. 2016). Locations with enough space for a Heligoland trap and where migration can be expected along the coast are: the Bunker-island at the Afsluitdijk near Den Oever (Figure 3.17), the 'gully' at the Hondsbossche Zeewering near de Putten (Figure 3.18), the outer dunes at Wijk aan Zee (Figure 3.19), and Neeltje Jans, an artificial island in the Netherlands in the province of Zeeland, halfway between Noord-Beveland and Schouwen-Duiveland in the Oosterschelde (Figure 3.20).

At present we are investigating the possibilities of co-operating with one or more of the location managers aimed at setting up a Heligoland trap in the autumn of 2017 or later.

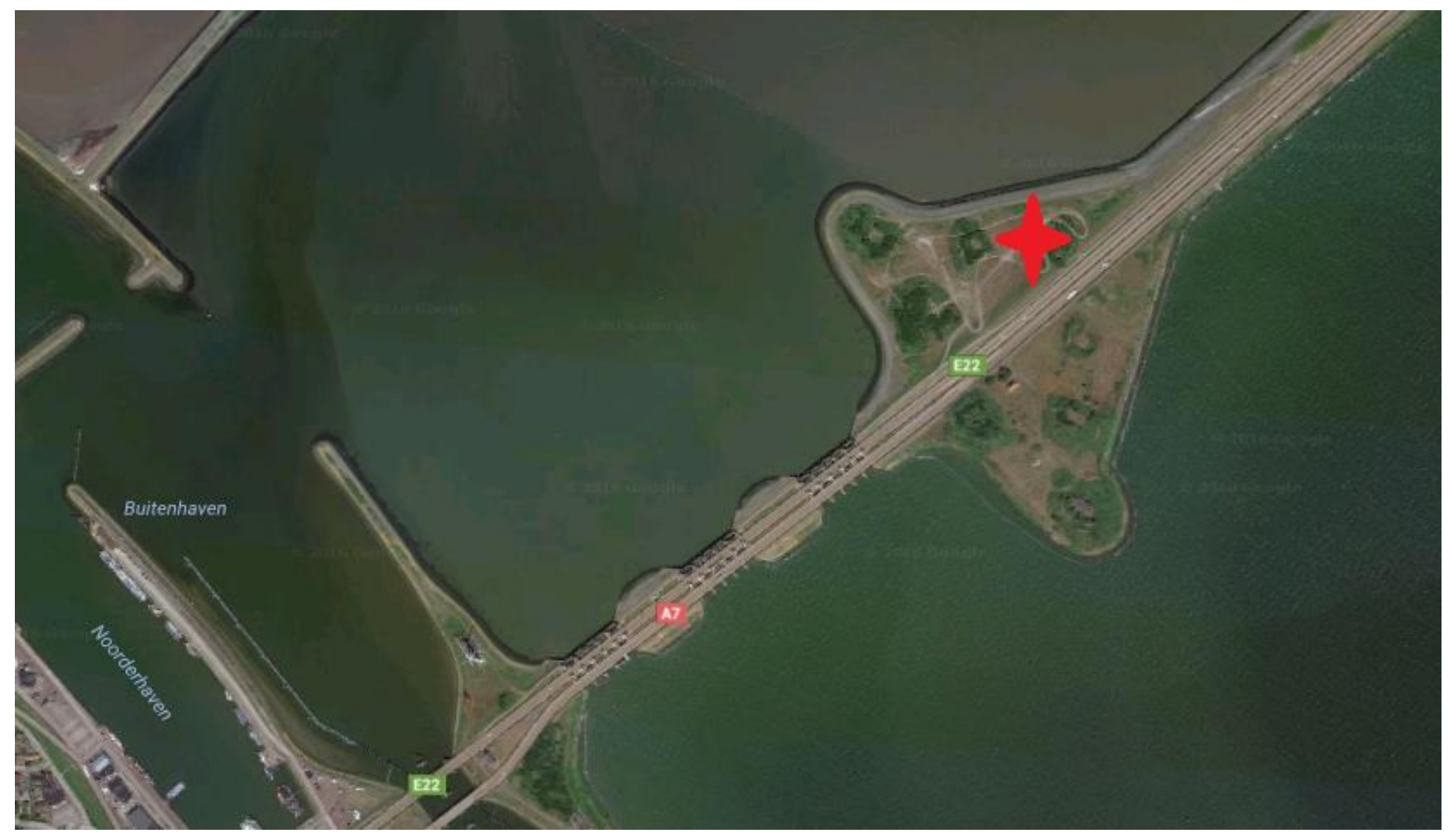

Figure 3.17: Bunker-island near Den Oever. 


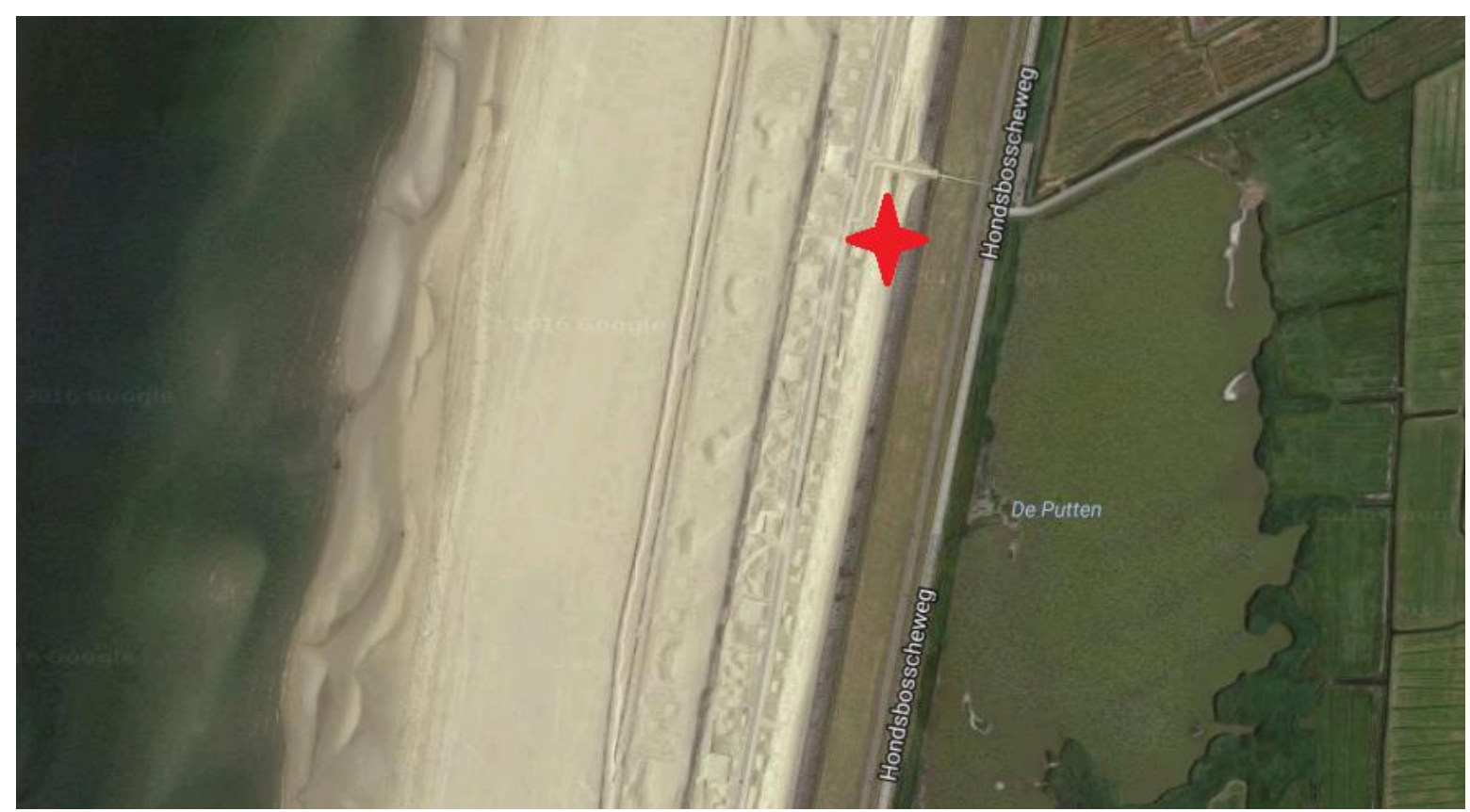

Figure 3.18: The gully at the Hondsbossche Zeewering.

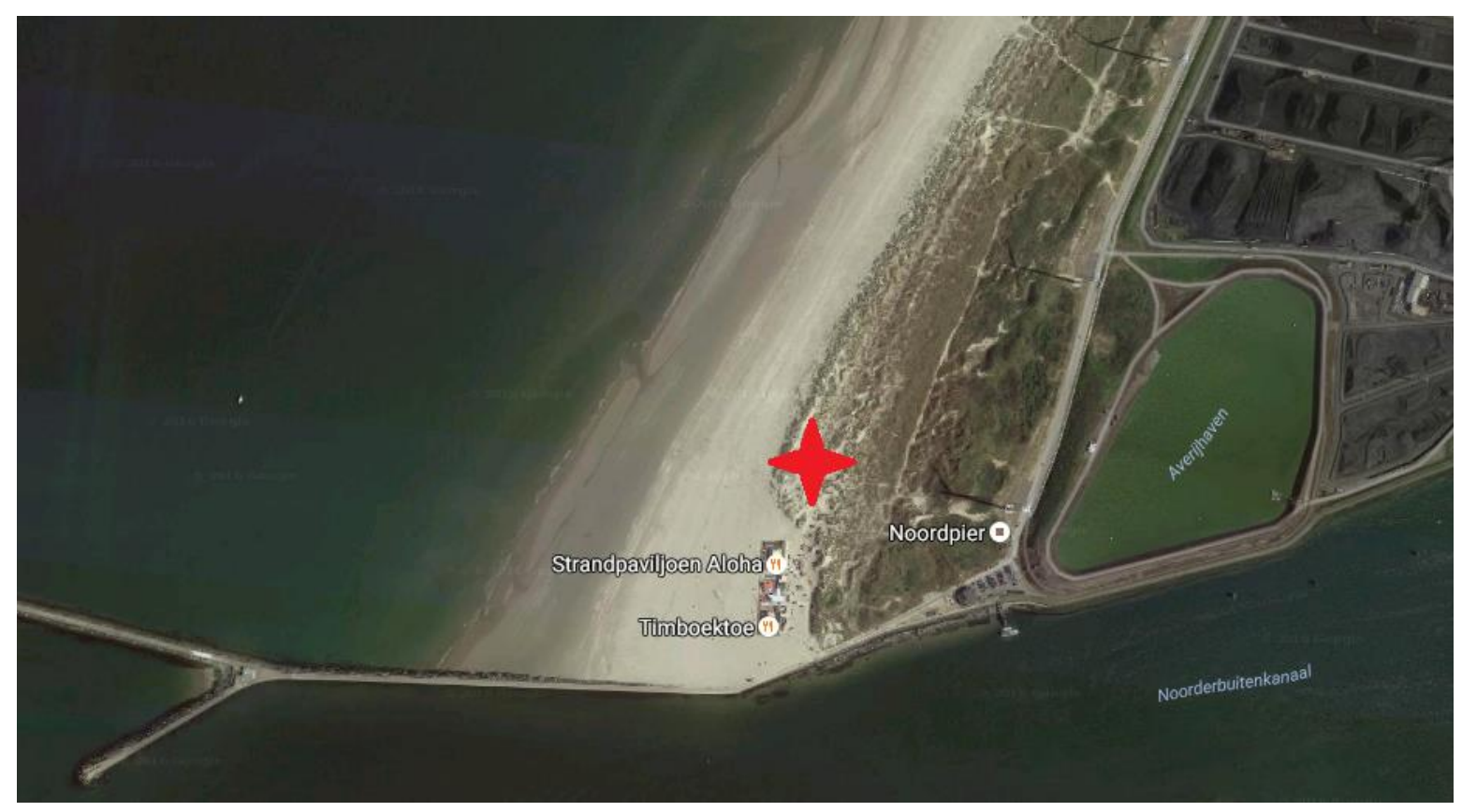

Figure 3.19: Outer dunes at Wijk aan Zee. 


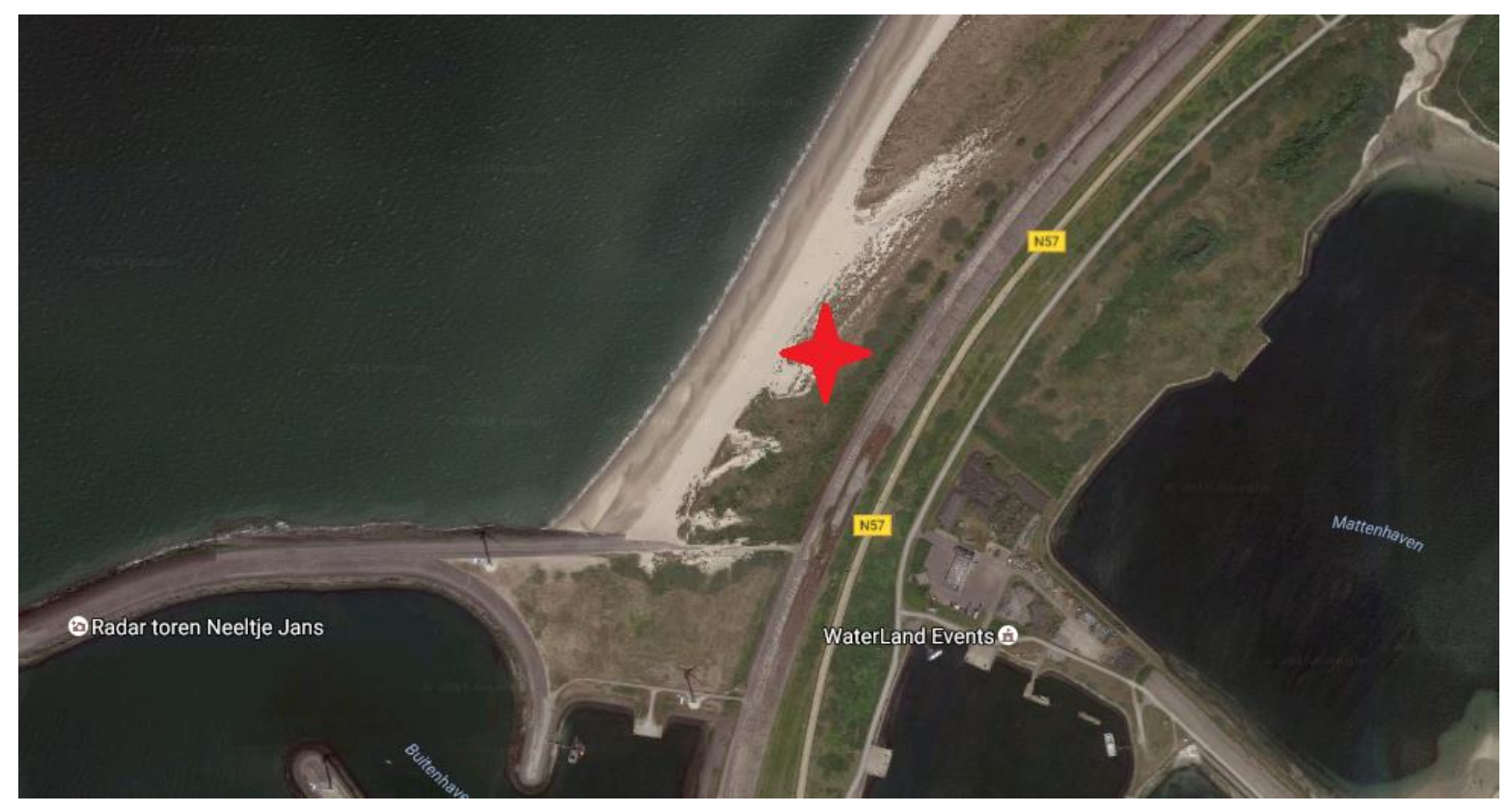

Figure 3.20: Outer dunes at Neeltje Jans. 


\section{Discussion and Conclusions}

\subsection{Technical infrastructure}

Because of the body weight of our main species of interest, Nathusius' pipistrelle, we can only apply radio (VHF) transmitter tags to follow their movements, as other devices will exceed the 5\%-weight threshold (Aldridge \& Brigham 1988, O’Mara et al. 2014).

There are several options to track bats with radio telemetry during their migration at the coast and over sea. The only realistic option for long-term monitoring of multiple individuals is a grid of receivers (Janssen et al. 2016). There are many examples from abroad where such a network is successfully applied (Sjöberg et al. 2015, Deppe et al. 2015, Rerucha et al. 2014, McGuire et al. 2011, Francis et al. 2016).

Several tests were carried out to test the performance of the technical infrastructure. The detection range of directional antennas can significantly be improved by increasing height above ground level of the receiver and using an antenna that has more elements. A further improvement of the detection range can be achieved when the height of the transmitter is increased.

Our preliminary tests showed that detection ranges of more than $6 \mathrm{~km}$ are realistic. Other researchers have achieved at least $10 \mathrm{~km}$ (pers. comm. Heiko Schmaljohan, Vogelwarte Helgoland) or even more than $15 \mathrm{~km}$ (pers. comm. Phil Taylor, Motus). The detection range of the omnidirectional antenna we tested was very small (a few $100 \mathrm{~m}$ ) compared with directional antennas. The detection range of the omnidirectional antenna might be increased (slightly) by attaching it to a plate (which acts as a reflector) or by using three radials on the base.

In conclusion, the tests conducted indicate that tracking migratory bats over large distances is possible using an array of receivers. The receivers should be installed at high structures (lighthouses, towers, buildings) in order to obtain detections over large distances. If relatively detailed information about the location of the tracked animal is required, the detection range of different (at least two) receiver stations should overlap as much as possible.

In the experimental setup for this study we did several tracking experiments. During one experiment we reached an accuracy of $104 \mathrm{~m}$ using the average algorithm, which we consider a good result. It is likely that the accuracy can be improved significantly by estimating the bearings of the received signals based on the signal strength of different antennas. Further improvements can probably be achieved by assessing the (likely) flight route with a state-space model (Patterson et al. 2008).

\subsection{International cooperation}

Recently, at the radio-telemetry conference in Lund, it appeared that there is strong support amongst European bird and bat researchers to set up a network of automated receivers, comparable to the network which has already been realised in Canada and the US. In addition, it was also agreed that data processing should be done by Motus, like in North America. The preferred common European frequency is $150.100 \mathrm{MHz}$.

To follow the movements of bats that have been tagged during prolonged periods of time and over wide areas, an extensive network of stationary receivers is needed. Motus provides such a network. By joining Motus, each registered project contributes to the work of other researchers as the receivers record all registered tagged animals. 


\subsection{Trapping bats}

Temperate zone bats have a relative high longevity in comparison with other mammals of their size, and a slow reproduction rate (Carranza 1996; Barclay and Harder 2003). Telemetry, which involves the capture and handling of bats and the attachment of a transmitter, should be performed with extreme care. For instance, faulty applied tags will inhibit the bat to perform its natural behaviour and in addition such bats may less likely cross the North Sea. In the Netherlands researchers working with bats (both handling and applying radio-tags) are expected to have a certificate issued by the Dutch bat trapping foundation (http://www.vleermuizenvangen.nl/).

Capturing bats in bat boxes is the most easy way of trapping. However, bat boxes are in general used as mating roosts by territorial males, and individual territorial males are likely to be present during prolonged periods. Migratory adult females and juveniles (including males) are often roosting in the bat boxes, but other adult males are not tolerated. Therefore, it is unlikely that actively migrating adult males are found in bat boxes. It seems wise to tag only females and juveniles from bat boxes, which are more likely to be on the move.

There are plenty of locations with bat boxes enabling us to trap potentially hundreds of individuals per season. In the Netherlands, probably the best study area for migratory bats is the province of NoordHolland where many bats (in particular Nathusius' Pipistrelles) enter the area over the Afsluitdijk and stop over at various locations with bat boxes.

A Heligoland trap can also be used to capture bats. If the Heligoland trap is set up at the coast, it is likely that actively migrating bats can be captured, including migrating (adult) males. It seems likely that the chances of detection by the grid of receivers is potentially much higher when tagging actively migrating bats. We identified four different locations where migration can be expected and where a Heligoland trap can be set up. Obtaining the necessary permits to set-up a Heligoland at the coast however, may be a challenge. 


\section{Recommendations}

We advise to realise a network of at least 15 receiving stations in 2017 in Noord-Holland near the capture locations, and further south (inland and at the coast), as well as at one or two locations at sea. A significant number of bats (100-200) should be tagged each year to determine the migration directions (over land and over sea), and the proportion of the population that apparently does not migrate. Migratory bats can be captured in bat boxes.

If the numbers of tagged bats from the bat boxes that travel along the coast and/or depart to sea turn out to be limited, the realisation of a Heligoland trap at the Hondsbossche Zeewering should be considered. This will enable us to actively capture migrating bats of which the migration direction can be determined when receiver stations are installed at the coast, and perhaps also less individuals are needed to obtain enough data.

We advise to set up 5-10 additional telemetry receiver stations in offshore wind farm OWEZ and/or PAWP (although the latter location seems less representative of future turbine configurations/sizes) and/or LUD, after the tracking system has proven itself on land. This will enable us to study the behaviour of bats on a larger scale in and nearby offshore wind farms (attraction, staging times, etc).

Another location with high potential for telemetry is the area around Westkapelle. From there, migratory bats may follow the Belgian coastline after crossing the Westerschelde or continue to fly over sea. Doing the latter it is likely that they will pass through the Belgian offshore wind farms which are located at approximately $20 \mathrm{~km}$ from Westkapelle. With 5 receivers it should be possible to track bats departing from that general area, and assess whether they follow the Belgian coastline or fly over open sea to the Belgian wind farms. It is recommended to seek cooperation with Belgian research groups and institutes (RBINS is already interested) to try and expand the grid of receivers along the Belgian coastline and in adjacent offshore wind farms.

Bat boxes, in good numbers, are not present around Westkapelle at this moment. Therefore, at least 100 bat boxes should be mounted in (patches of) forest in that area in order to be able to capture bats. Bats in general do not use bat boxes during the first year. Thus, if telemetry around Westkapelle is implemented, the bat boxes should be realised at least one year before the actual start of a monitoring project.

Joining a wildlife tracking system like Motus (Canada) in order to enlarge the data collection, is highly recommended. Motus-members can get detections from both their own tags received by stations owned by other members, and from tags owned by other members if received by their own stations.

If a full telemetry study is considered, attention should be given to timely obtaining the necessary permits, e.g. under the Dutch Nature protection legislation (Wet natuurbescherming, effective from 1 January 2017). 


\section{Quality Assurance}

Wageningen Marine Research utilises an ISO 9001:2008 certified quality management system (certificate number: 187378-2015-AQ-NLD-RvA). This certificate is valid until 15 September 2018. The organisation has been certified since 27 February 2001. The certification was issued by DNV Certification B.V. 


\section{References}

Aldridge H.D.J.N. \& R.M. Brigham, 1988. Load carrying and maneuverability in an insectivorous bat: a test of the 5\% "rule" of radiotelemetry. Journal of Mammalology 69: 379-382.

Bach P., Bach L. \& K. Ekschmitt 2014. Bat activities and bat fatalities at different wind farms in Northwest Germany. Book of Abstracts XIIIth European Bat Research Symposium, Sibenik, Croatia.

Baerwald E.F., G.H. D'Amours, B.J. Klug \& R.M.R. Barclay 2008. Barotrauma is a significant cause of bat fatalities at wind turbines. Current Biology 18: 695-696.

Barclay R.M. \& D. Harder 2003. Life histories of bats: life in the slow lane. Bat ecology, pp. 209-253.

Boshamer J.P.C. \& J.P. Bekker 2008. Nathusius' pipistrelles (Pipistrellus nathusii) and other species of bats on offshore platforms in the Dutch sector of the North Sea. Lutra 51: 17-36.

Carranza J. 1996. Sexual selection for male body mass and the evolution of litter size in mammals. Am Nat: 81-100.

Cryan P.M., P.M. Gorresen, C.D. Hein, M.R. Schirmacher, R.H. Diehl, M.M. Huso, D.T.S. Hayman, P.D. Fricker, F.J. Bonaccorso, D.H. Johnson, K. Heist \& D.C. Dalton 2014. Behavior of bats at wind turbines. www.pnas.org/cgi/doi/10.1073/pnas.1406672111.

Deppe J.L., M.P. Ward, R.T. Bolus, , R.H. Diehl , A. Celis-Murillo , T.J. Zenzal F.R. Moore, T.J. Benson, J.A. Smolinksy, L.N. Schofield, D.A. Enstrom, E.H. Paxton, G. Bohrer,T.A. Beveroth, A. Raim, R.L. Obringer, D. Delaney, W.W. Cochran 2015. Fat weather, and date affect migratory songbirds' departure decisions, routes, and time it takes to cross the Gulf of Mexico. Proceedings of the National Academy of Sciences of the United States of America 112(46): E6331-E6338.

doi:10.1073/pnas.1503381112.

Francis C.M., P.D. Taylor \& Z.J. Crysler 2016. Motus Wildlife Tracking System: a novel approach for tracking small birds. BOU Proceedings - Birds in time and space: avian tracking and remote sensing. http://www.bou.org.uk/bouproc-net/tracking/poster-francis-etal.pdf Proceedings of the BOU's 2015 Annual Conference | \#BOU2015. Birds in time and space: avian tracking and remote sensing.

Janssen R., A.J. Haarsma \& S. Lagerveld 2016. Pilotonderzoek vleermuizen vangen en volgen over zee. IMARES, Report C038/16.

Jonge Poerink B., S. Lagerveld \& H. Verdaat 2013. Pilot study bat activity in the Dutch offshore wind farms OWEZ and PAWP (2012). IMARES report C026/13.

Holland R.A., J.L. Kirschvink, T.G. Doak \& M. Wikelski 2008. Bats use magnetite to detect the earth's magnetic field. PlosOne 3:e1676.

Kapteyn K. 1995. Vleermuizen in het landschap. Over hun ecologie, gedrag en verspreiding. Schuyt \& Co uitgeverij.

Kays R., S. Tilak, M. Crofoot, T. Fountain, D. Obando, A. Ortega, F. Kuemmeth, J. Mandel, G. Swenson, T. Lambert, B. Hirsch \& M. Wikelski 2011. Tracking animal location and activity with an automated radio telemetry system in a tropical rainforest. The Computer Journal, bxr072

Kenward R.E. 2007. A manual for Wildlife tracking. Academic press. ISBN 0-12-404242-2 
Körner F., R. Speck, A.H. Göktogan \& S. Sukkarieh 2010. Autonomous airborne wildlife tracking using radio signal strength. In Intelligent Robots and Systems (IROS), 2010 IEEE/RSJ International Conference on (pp. 107-112). IEEE.

Lagerveld S., B .Jonge Poerink, \& H. Verdaat 2014a. Monitoring bat activity in offshore wind farms OWEZ and PAWP in 2013. IMARES Report C165/14.

Lagerveld S., B. Jonge Poerink, R. Haselager \& H. Verdaat 2014b. Bats in Dutch offshore wind farms in autumn 2012. Lutra 57 (2): 61-69

Lagerveld S., B. Jonge Poerink \& P. de Vries 2015. Monitoring Bat activity at the Dutch EEZ in 2014. IMARES Report C094/15.

Leopold M.F., M. Boonman, M.P. Collier, N. Davaasuren, R.C. Fijn, A. Gyimesi, J. de Jong R.H. Jongbloed, B. Jonge Poerink, J.C. Kleyheeg-Hartman, K.L. Krijgsveld, S. Lagerveld, R. Lensink, M.J.M. Poot, J.T. van der Wal \& M. Scholl 2014. A first approach to deal with cumulative effects on birds and bats of offshore wind farms and other human activities in the Southern North Sea. IMARES Report C166/14

MacCurdy R., R. Gabrielson, E. Spaulding, A. Purgue, K. Cortopassi, K. Fristrup 2009. Automatic animal tracking using matched filters and time difference of arrival. Journal of Communications 4: 487-495.

McCracken G.F., K. Safi, T.H. Kunz, D.K. Dechmann, S.M. Swartz \& M. Wikelski 2016. Airplane tracking documents the fastest flight speeds recorded for bats. Open Science, 3(11), 160398.

McGuire L.P., C.G. Guglielmo, S.A.Mackenzie \& P.D. Taylor 2011. Migratory stopover in the longdistance migrant silver-haired bat, Lasionycteris noctivagans. Journal of Animal Ecology. doi: 10.1111/j.1365-2656.2011.01912.x.

O'Mara M. T., M. Wikelski \& D.K.N. Dechmann 2014. 50 years of bat tracking: device attachment and future directions. Methods in Ecology and Evolution, 5: 311-319. doi: 10.1111/2041-210X.12172

Patterson T.A., L. Thomas, C. Wilcox, O. Ovaskainen\& J. Matthiopoulos 2008. State-space models of individual animal movement. Trends in Ecology \& Evolution, 23, 87-94

Rerucha S., T. Bartonicka, P. Jedlicka, M. Cížek, O. Hlouša, R Lucan \& I. Horácek 2014. The BAARA (Biological AutomAted RAdiotracking) System: A New Approach in Ecological Field Studies. PLoS ONE 10(2): e0116785. doi:10.1371/journal. pone.0116785

Safi K., B. König \& G. Kerth 2007. Sex differences in population genetics, home range size and habitat use of the parti-colored bat (Vespertilio murinus, Linnaeus 1758) in Switzerland and their consequences for conservation. Biological Conservation, 137(1), 28-36.

SER Agreement 2013. http://www.energieakkoordser.nl/doen/engels.aspx [last accessed: December 2017]

Sjöberg S., T. Alerstam, S. Åkesson, A. Schulz, A. Weidauer , T. Coppack \& R. Muheim 2015. Weather and fuel reserves determine departure and flight decisions in passerines migrating across the Baltic Sea. Animal Behaviour, 104, 59-68.

Smolinsky J.A., R.H.Diehl, T.A. Radzio, D.K.Delaney \& F.R. Moore 2013. Factors influencing the movement biology of migrant songbirds confronted with an ecological barrier. Behavioral Ecology and Sociobiology, 67(12), 2041-2051. 
Springer J.T. 1979. Some sources of bias and sampling error in radio triangulation. The Journal of Wildlife Management, 926-935.

Swihart R.K. \& N. A. Slade 1985. Influence of sampling interval on estimates of home-range size. The Journal of Wildlife Management, 1019-1025.

Taylor K.D. \& H.G. Lloyd 1978. The design, construction and use of a radio-tracking system for some British mammals. Mammal Review, 8(4), 117-141. 


\section{Justification}

Report C011/17

Project Number: 43151000.38

The scientific quality of this report has been peer reviewed by a colleague scientist and a member of the Management Team of Wageningen Marine Research

Approved: $\quad$ dr. ir. H.V. Winter

Scientific researcher

Signature:

Date:

28 February 2017

Approved: $\quad$ drs. J.A. Asjes

Member of Management Team

Signature:

Date:

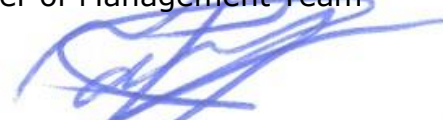


Annex 1 Lund Conference 2016 


\section{Automated Radiotelemetry in Europe, Lund 15-16 June 2016}

Most important outcomes from the meeting:

- Everyone should apply for permission to work on $150.100 \mathrm{MHz}$ for now and the process for applying for a joint European frequency will be initiated.

- We will be a part of Motus.

- A mail list will be created for communication within the network.

- A work group was formed that will work out guidelines for a future European organization.

Notes from the meeting:

\section{WEDNESDAY 15 JUNE}

- Susanne Åkesson and Sissel Sjöberg opened the meeting and greeted everyone welcome.

- Sissel Sjöberg continued with a talk on the radiotelemetry project in Falsterbo, southwestern Sweden.

- All participants introduced themselves and their project in the order from the programme, (appendix 1).

- Arne Andersson and Rachel Muheim talked about the problem that we have to work on the same frequency in Europe. As the situation is at the moment we do not have one frequency that we all have permission to work on ("Frequencies used" appendix 2), and to apply for a mutual European frequency will take many years, probably up to a decade. There is also frequencies that might be open in the entire Europe, but we need to look into this closer in order to be sure and to see how well they could work for our purpose ("Frequency allocations, short range devices" appendix 2). These open frequencies might have some drawbacks; that they are open for everyone means that disturbances could be expected, and the wavelengths might not be optimal for animal tracking. As a start the meeting decided that we all will apply to work on the German frequency open for animal tracking, $150.100 \mathrm{MHz}$, as that is the frequency most people work with. At the same time we will prepare an application for a joint European frequency.

- The day ended with a pizza evening, with mingle and bar. 


\section{THURSDAY 16 JUNE}

- Group discussions:

"Scientific questions and future research" Arne Hegemann

Main interests:

- We identified two main purposes for what a European network of automated radio-telemetry can be used for/ is needed for:

- A) fundamental research; this includes testing theory, identifying migration routes, stopover ecology, arrival biology, relating physiological data to migration performance, experimental approaches

- B) applied science; especially identifying migration corridors in relation to wind farm planning (mostly nocturnal migration)

- Main interest are birds and bats for both parts, but insects could possibly be included in the future

- For both main purposes, stations offshore and inland are valuable

- Possibility to track young birds is promising; usually we lack tracking data of young birds, because their low return rates make studies with loggers unattractive

- For bird observatories such a network could be a way to get a scientific boost and connect new data with long-term ringing data

- Regarding bats, data from such a network could help validating activity data currently collected from automated bat detectors

Geographical coverage:

- We identified a number of areas where receiving stations would be very welcome: Gibraltar, Bosporus, Pyrenees, France, Poland, Italy, Alps, Israel

- The first focus should be on bottlenecks

- stations offshore and inland are valuable for both scientific research and applied science (see above)

- we should actively approach the seabird community; they have potentially access to strategic point and the possibility to track young birds might be attractive for them (see above)

- we should try to get stations on oil-platforms; companies are often very open to collaborations/scientific research

Scientific board:

- It would be good to have a scientific board, which can overlook all projects, can identify possible collaborations, connect people and write joint big grant proposals; we stressed that this will not impact the autonomy of each single project. Every group can work on whatever they want and are totally independent; the scientific board would only (help to) facilitate additional large-scale projects and coordinates what goes beyond local projects

- Having a basic network that works will make it much easier to apply for big funding 
Species:

- All local projects can work on whatever they want; we should not limit it to certain species

- Only when we apply for money for a big joint project we will need to focus on a few target species

- In bats are only about 4-5 (possibly) migrating species

- $\quad$ Regarding birds working on short-distance migrants might be promising because the currently planned stations will cover (part of) breeding, migration and wintering areas

Other:

- It will be important to link a transmitter not only to a bird ID but also to the standard EURING data (weight, fat score, wing length etc.) to make data more valuable

- We need a good system of informing each other what type of data is available

- The EOU (European Ornithologists' Union) could be a good platform for our network

\section{"Data and how to share information" Rachel Muheim}

How can we exchange information on which tags are "in the air" and who deployed them? How can we coordinate the use of different tag IDs so that there is no overlap?

- If we use the Motus system [which we later decided to do], their database will keep track of which tags are used by whom and inform the tag users on which "foreign" stations the tag has been heard. Regarding deployment of different tag IDs and the potential problem of overlap: in North America, Lotek makes sure to not fabricate tags with the same IDs during one year, since they are currently the only producer of ID tags. It is, however, also possible for other companies/research groups to manufacture ID tags that can be perceived by sensorgnomes, and the data processed by Motus. Phil Taylor explains how this works in detail.

- Integration of Motus data into Movebank is mentioned to be under way, so that telemetry data in the future can be accessed and viewed through Movebank.

\section{"Organization" Sissel Sjöberg}

What do we expect from a European network on radiotelemetry?

- Expertise network, to make progress reports. Inform about problems, open up new collaborations, direct future developments.

What do we want a workgroup to do?

- To start with the work group should work as a preparatory group, which will outline how the organization will look in the future, prepare the layout for the future and establish a procedure for people who want to join. In the future several groups with different functions might be a good idea (e.g. technical, one group that deals with legal issues, one group that work more with 
the science etc.), important that the "steering board" in the end should include people from all interests (academia, bird observatories, applied ecology and so on). To rule out efforts and costs? Coordination of projects, trouble shooting groups, be a part of EURING? Movebank? MLBS? Work out guidelines for which information we should share with each other. Authorship? Some groups sees the "bonus" as the fundamental part of their project, might be a problem.

Who should be a part of this workgroup?

- One person per country who wants to join to start with. Centralization within countries and meetings via internet. In the future max 10 persons, optimal 5-8 persons.

Is there people that we haven't been able to reach and how to reach them?

- EOU-MLSG? BirdLife? National ringing schemes, ethical committees (gives the permission), BatLife, insect people?

Other:

- Fundraising: let everyone else know how you did. Help each other to get funding, share experiences. Collaboration towards citizen science, bird organizations. Wind farms? Be clear with the power of the system from an academia side to get funding from the industry.

- Short summary of the different discussions with all participants. Arne Hegemann informed about the possibility to use EOU as a platform for website.

- Discussion on who should be a part of the work group that will work more actively with organising how we want the European organization to look like. This group will further start the application process of a European frequency, firstly by looking into what we need to do and how, and secondly by either doing it themselves or organising a group that will do this. Since some of the problems we might run into can be national dependent we decided that one representative from each participating country can be a good start.

Members of the work group:

Kathrine Snell - Denmark

Maarten Platteeuw - Netherlands

Ivan Maggini - Austria

Erich Bächler - Switzerland

Vera Brust - Germany

Robin Brabant - Belgium

Samantha Franks - UK/Ireland

Terje Axelsen - Norway

Andrey Mukhin - Russia

Sissel Sjöberg - Sweden

Sissel Sjöberg will work as convenor and will also create a network mail list with all participants and everyone that has declared interest in the subject but could not join this meeting. 
- Should we be a part of Motus or not? Phil Taylor told us some more about the benefits of joining them, and some functions of their website (http://www.birdscanada.org/research/motus/ and http://motus-wts.org/ ). Everyone at the meeting agreed on the advantage to spend time and money on developing and expanding our systems, instead of redoing all the work that Motus already have done, and we took a joint decision that we all should be a part of Motus in the future.

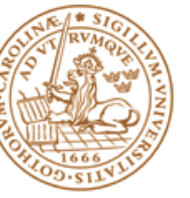




\section{Annex 2 Signals per antenna/receiver}

Figures $\mathrm{A} 1$ and $\mathrm{A} 2$ show the received signals per antenna at the various receiver stations for both tracking experiments (section 3.3). Note the increase/decreases in the received signals when approaching/moving away or changing the angle of the transmitter antenna in relation to the receiver antenna.
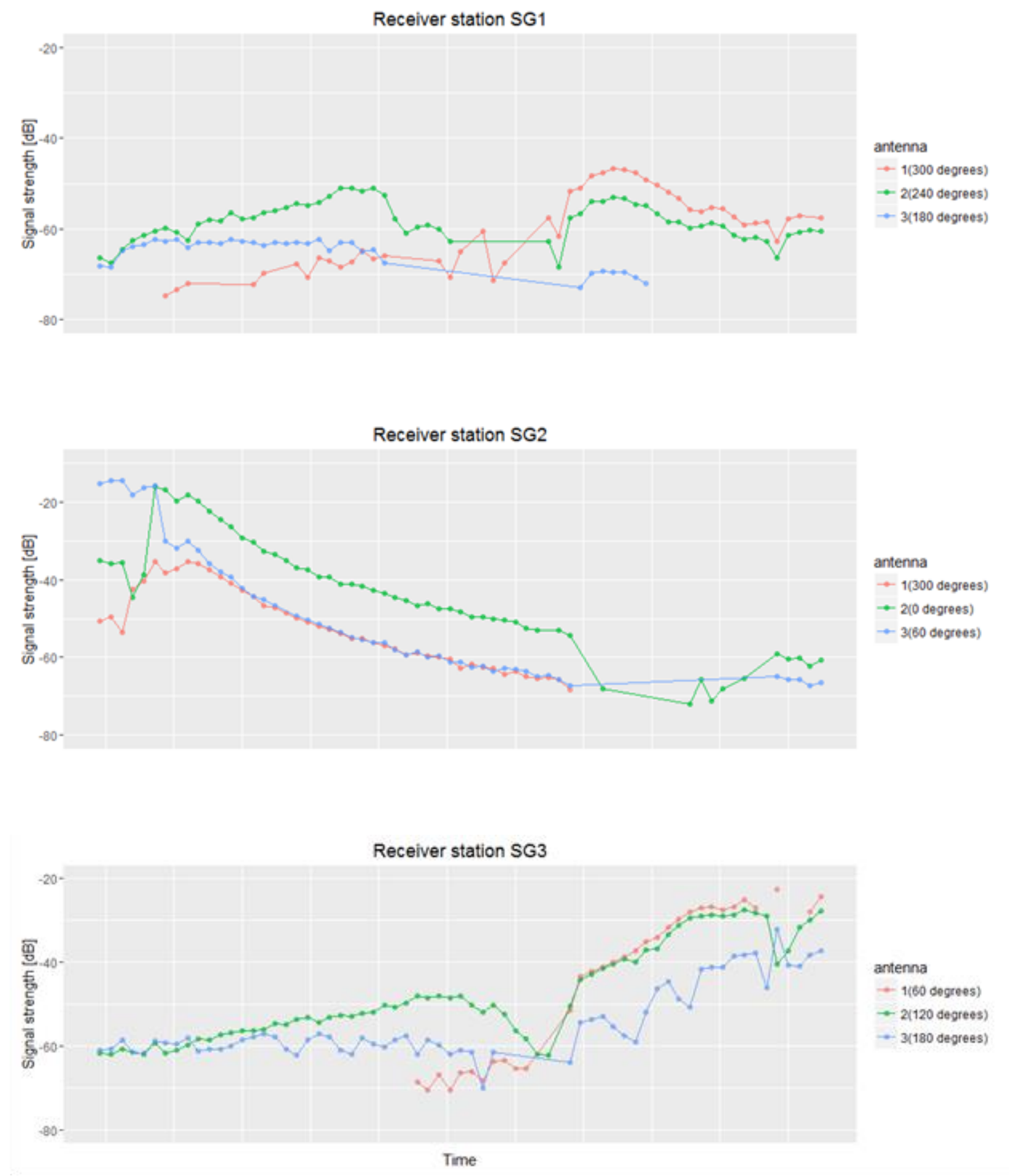

Figure A1: Signals per antenna at the various receiver stations during the first tracking test. 

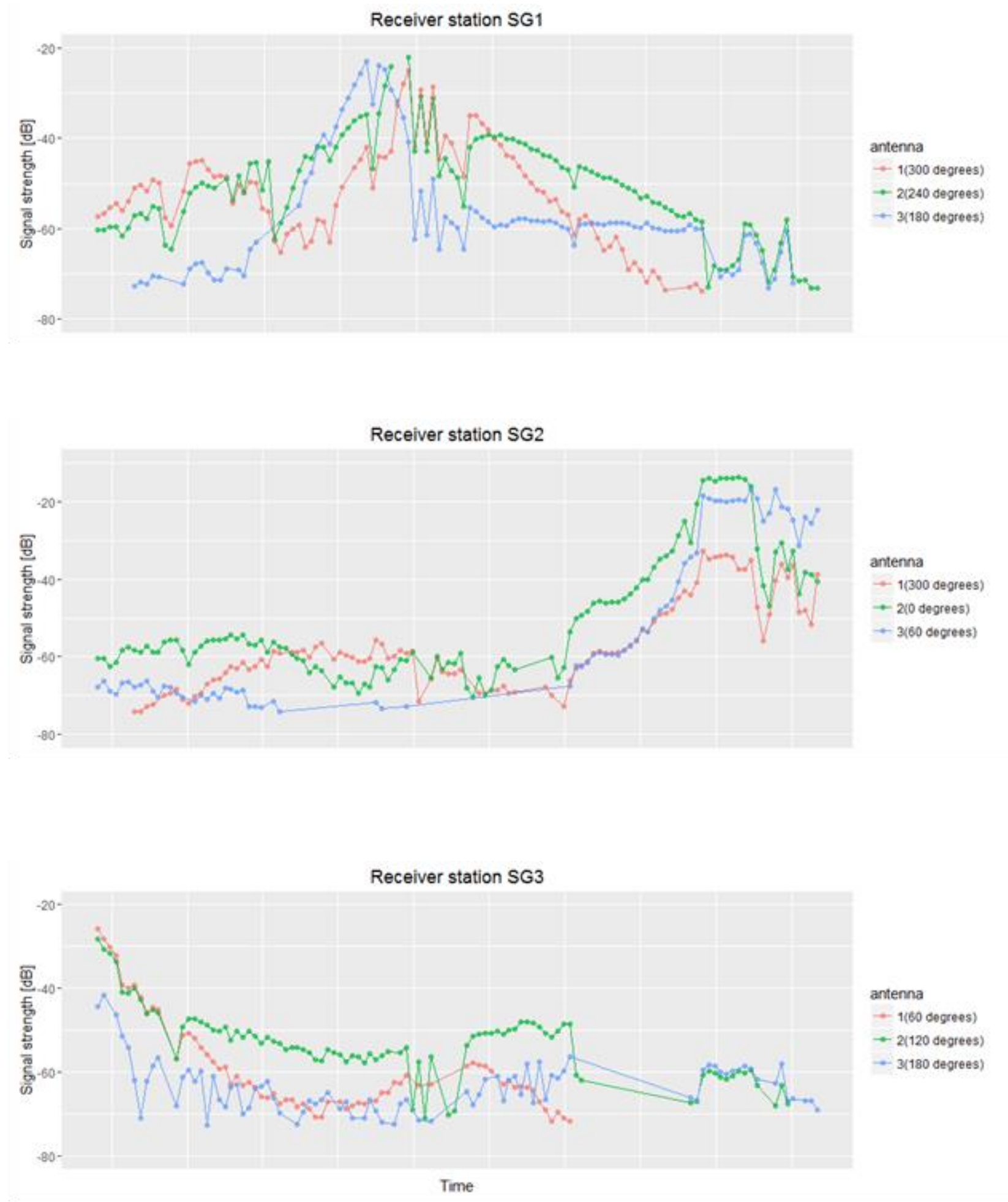

Figure A2: Signals per antenna at the various receiver stations during the second tracking test. 
Wageningen Marine Research

T +31 (0)317480900

E: marine-research@wur.nl

www.wur.eu/marine-research

Visitors' address

- Ankerpark 271781 AG Den Helder

- Korringaweg 5, 4401 NT Yerseke

- Haringkade 1, 1976 CP IJmuiden
Wageningen Marine Research is the Netherlands research institute established to provide the scientific support that is essential for developing policies and innovation in respect of the marine environment, fishery activities, aquaculture and the maritime sector.

\section{Wageningen University \& Research:}

is specialised in the domain of healthy food and living environment.

\section{The Wageningen Marine Research vision}

'To explore the potential of marine nature to improve the quality of life'

\section{The Wageningen Marine Research mission}

- To conduct research with the aim of acquiring knowledge and offering advice on the sustainable management and use of marine and coastal areas.

- Wageningen Marine Research is an independent, leading scientific research institute

Wageningen Marine Research is part of the international knowledge organisation Wageningen UR (University \& Research centre). Within Wageningen UR, nine specialised research institutes of the Stichting Wageningen Research Foundation have joined forces with Wageningen University to help answer the most important questions in the domain of healthy food and living environment. 